University of Tennessee Health Science Center UTHSC Digital Commons

$12-1993$

\title{
Pain and Hospital Patients Perception of Quality
}

Kathy L. Beck

University of Tennessee Health Science Center

Follow this and additional works at: https://dc.uthsc.edu/dissertations

Part of the Health and Medical Administration Commons, Health Services Administration Commons, Health Services Research Commons, and the Nursing Administration Commons

\section{Recommended Citation}

Beck, Kathy L. , "Pain and Hospital Patients Perception of Quality" (1993). Theses and Dissertations (ETD). Paper 420. http://dx.doi.org/10.21007/ptd.cghs.1993.0423.

This Dissertation is brought to you for free and open access by the College of Graduate Health Sciences at UTHSC Digital Commons. It has been accepted for inclusion in Theses and Dissertations (ETD) by an authorized administrator of UTHSC Digital Commons. For more information, please contact jwelch30@uthsc.edu. 


\title{
Pain and Hospital Patients Perception of Quality
}

\begin{abstract}
Each year pain disables approximately 50 million Americans. These patients seekhealth care for the relief of pain and its underlying cause. Many of those seeking relief from pain are hospitalized and others experience pain during their hospitalization. All of these patients have the right to relief of their pain and none should suffer pain needlessly. Yet, often nurses fail to accurately assess and adequately manage patients' pain.
\end{abstract}

Adequate pain management may increase patient perception of nursing care quality. The purpose of this study is to determine the relationships between pain relief and patients' and nurses' perceptions of quality. The relationship between the adequate treatment of pain and patients' perceptions of quality has not been examined. However, one study by Larrabee examined the relationship between severity of pain on exit interview and patient's perceptions of quality and found an inverse relationship.

This study was a secondary analysis of a study by Larrabee. The sample included a subset $(N=91)$ of the original 199 patients. This subset consisted of the patients who reported pain as their chief compliant, stated relief of pain as one of their three goals for hospitalization, and included the nursing diagnosis, "Alteration in Comfort, Pain; Actual" in the plan of care. This study tested the relationships among patient quality, value, and beneficence; and between patient quality, nurse quality, and nurse value; as proposed in Larrabee's model of quality.

There were three key findings. A positive relationship was demonstrat ed between patient-perceived quality and patient goal achievement Also, a positive relationship was demonstrated between both measures of patient value. Second, this study failed to demonstrate a relationship between patientperceived quality and diminished pain. However, a positive relationship was demonstrated between patient goal achievement and diminished pain. Third, this study failed to demonstrate a relationship between patient-perceived quality and nurse-perceived quality.

The implications for nursing executives are 1) to further explore the relationship between patient goal achievement for pain and achievement of other goals, 2) to pursue avenues to increase mutual goal setting in order to increase patient-perceived quality, 3) to pursue avenues to effectively manage patients' pain because diminished pain is associated with higher patient goal achievement, which, in turn, is associated with higher patient-perceived quality, and 4) to further explore the relationship between patient-perceived quality and nurse-perceived quality. Such investigations should provide nursing executives with additional information that could guide quality improvement efforts.

In conclusion, nursing executives have humanitarian and economic incentives to improve pain management, mutual goal setting, development of pain management plan with patient and interdisciplinary collaboration, evaluation of pain management effectiveness, and to further investigate the relationships among patient quality, patient value, nurse quality, and nurse value, and pain. The humanitarian incentive is a pain free patient receiving quality care. Because patient satisfaction is directly related to patients intent to return, intent to recommend, and intent to sue, the economic incentive is market share

maintenance, a strong incentive in today's highly competitive market

\section{Document Type}

Dissertation 


\section{Degree Name}

Master of Science (MS)

\section{Program}

Nursing

\section{Research Advisor}

Sylvia C. Price

\section{Keywords}

pain management, nursing care quality, hospitalization

\section{Subject Categories}

Health and Medical Administration | Health Services Administration | Health Services Research | Medicine and Health Sciences | Nursing | Nursing Administration 
PAIN AND HOSPITAL PATIENTS' PERCEPTIONS OF QUALITY

\author{
A Thesis \\ Presented to the Faculty \\ of the \\ College of Nursing \\ of
}

The University of Tennessee, Memphis

In Partial Fulfillment

of the Requirements for the Degree

Master of Science in Nursing

from The University of Tennessee

by

Kathy L. Beck

December 1993 


\section{WY \\ $1393 \mathrm{Bp}$ \\ ACKNOWLEDGMENTS}

I would like to thank my chairman and committee for their unending patience, support, and guidance in the writing of this thesis. A special note to my chairman, who has served as a mentor and support system throughout this program. In addition, I would like to thank several others.

First, my husband, who has continually taken responsibilities off my shoulders and bore the burden of these responsibilities himself, allowed me the freedom to complete this program. More importantly, I thank him for being my best friend and my support through this program by constantly reminding me to keep my eyes on the final goal.

Second, I would like to thank my parents and grandparents who have always encouraged me to seek knowledge, reach for the stars, and not to be satisfied with less than what I want out of life. Last and most importantly, they have served as a beacon in time of need and as shining examples of faith.

Last, I thank all my family and friends who believed in me when I did not believe in myself and who have supported and prayed for me. Without your care and understanding, my journey would have been very bumpy. 


\section{DEDICATION}

This thesis is dedicated to the Light that guides my path. Also, this thesis is in loving memory of John Morris Veazey; Debra Ann Jenkins Vaughn; and Harry Jefferson Sartain, Sr.

John Morris Veazey, my maternal grandfather, left my life earlier this year, but he will never leave my heart. He always showed me love and who's love was a haven in time of trouble.

Debra Ann Jenkins Vaughn; my cousin, Matron-of-Honor, and best friend; left my life a short time ago, but will always walk beside me. She taught me the meaning of a true friend, in which you can confide all things.

Last, but not least, Harry Jefferson Sartain's quiet presence continues to remind me of a quiet strength that never fails. This strength is not displayed in such a way as to be boastful. Nevertheless, this strength is a very strong support that propels you forward and gives you strength in times of need. 


\begin{abstract}
Each year pain disables approximately 50 million Americans. These patients seek health care for the relief of pain and its underlying cause. Many of those seeking relief from pain are hospitalized and others experience pain during their hospitalization. All of these patients have the right to relief of their pain and none should suffer pain needlessly. Yet, often nurses fail to accurately assess and adequately manage patients' pain.
\end{abstract}

Adequate pain management may increase patient perception of nursing care quality. The purpose of this study is to determine the relationships between pain relief and patients' and nurses' perceptions of quality. The relationship between the adequate treatment of pain and patients' perceptions of quality has not been examined. However, one study by Larrabee examined the relationship between severity of pain on exit interview and patient's perceptions of quality and found an inverse relationship.

This study was a secondary analysis of a study by Larrabee. The sample included a subset $(\mathrm{N}=91)$ of the original 199 patients. This subset consisted of the patients who reported pain as their chief compliant, stated relief of pain as one of their three goals for hospitalization, and included the nursing diagnosis, "Alteration in Comfort, Pain; Actual" in the plan of care. This study tested the relationships among patient quality, value, and beneficence; and between patient quality, nurse quality, and nurse value; as proposed in Larrabee's model of quality.

There were three key findings. A positive relationship was demonstrated between patient-perceived quality and patient goal achievement. Also, a positive relationship was demonstrated between both measures of patient value. Second, this study failed to demonstrate a relationship between patient-perceived quality and diminished pain. However, a positive relationship was demonstrated between patient goal achievement and 
diminished pain. Third, this study failed to demonstrate a relationship between patientperceived quality and nurse-perceived quality.

The implications for nursing executives are 1) to further explore the relationship between patient goal achievement for pain and achievement of other goals, 2) to pursue avenues to increase mutual goal setting in order to increase patient-perceived quality, 3) to pursue avenues to effectively manage patients' pain because diminished pain is associated with higher patient goal achievement, which, in turn, is associated with higher patientperceived quality, and 4) to further explore the relationship between patient-perceived quality and nurse-perceived quality. Such investigations should provide nursing executives with additional information that could guide quality improvement efforts.

In conclusion, nursing executives have humanitarian and economic incentives to improve pain management, mutual goal setting, development of pain management plan with patient and interdisciplinary collaboration, evaluation of pain management effectiveness, and to further investigate the relationships among patient quality, patient value, nurse quality, and nurse value, and pain. The humanitarian incentive is a pain free patient receiving quality care. Because patient satisfaction is directly related to patients intent to return, intent to recommend, and intent to sue, the economic incentive is market share maintenance, a strong incentive in today's highly competitive market. 
I. INTRODUCTION _.............................................................

Purpose of the Study ................................................................... 2

Justification for the Study ............................................................... 2

Conceptual Framework ................................................................ 5

Overview of the Conceptual Framework ……….......................... 5

Operationalization of the Concepts ………................................... 7

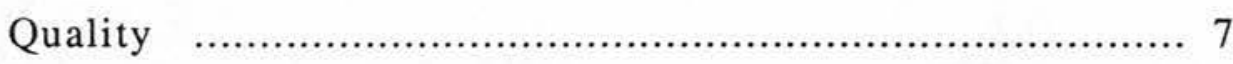

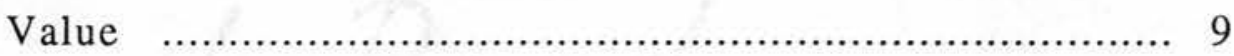

Beneficence …...................................................... 9

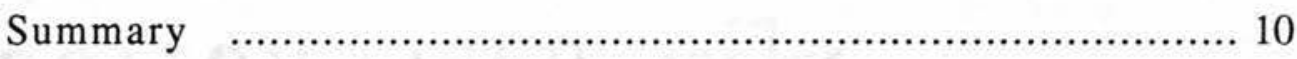

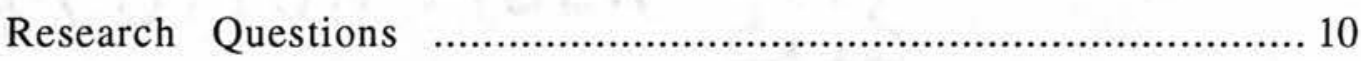

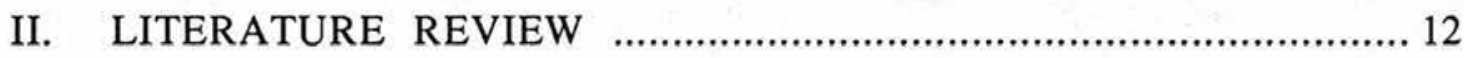

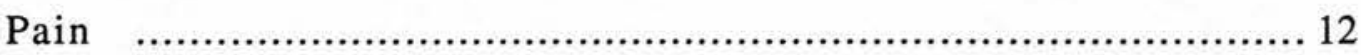

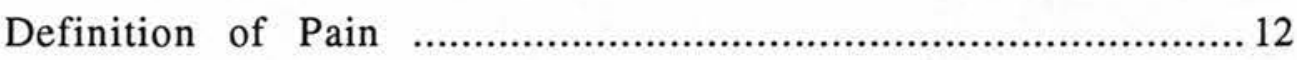

Overview …................................................................... 12

Pain Assessment .................................................................... 14

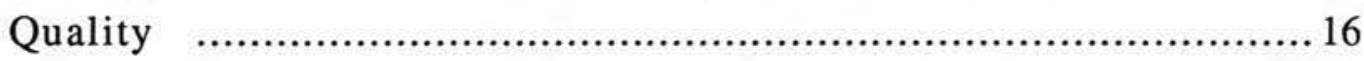

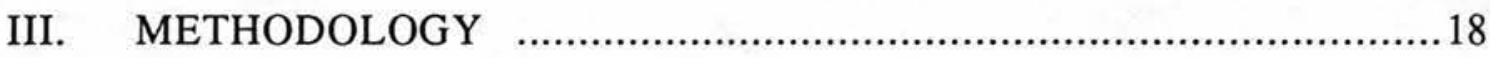

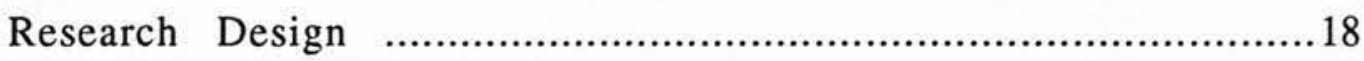

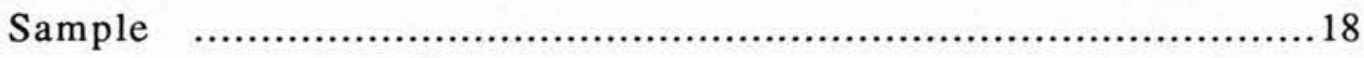

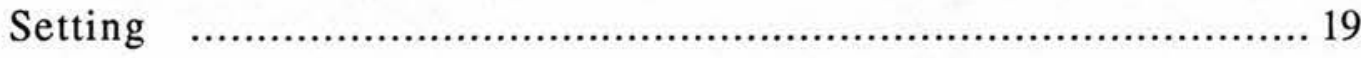

Measurement of Patient and Nurse Variables ......................................... 19

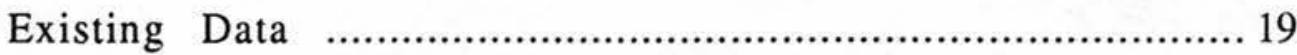


Patient-perceived quality f.................................................. 19

Patient goal achievement .................................................... 19

Pain diminished intensity score ………………......................21

Nurse-perceived quality for pain ............................................ 21

Nurse goal achievement for pain .......................................... 21

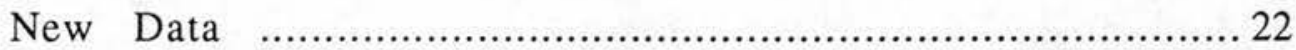

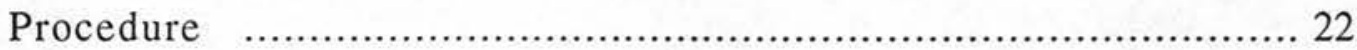

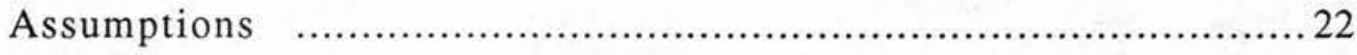

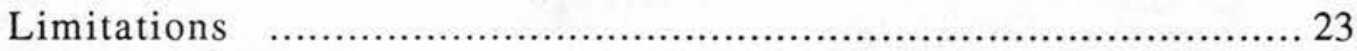

Protection of Human Subjects ...................................................... 24

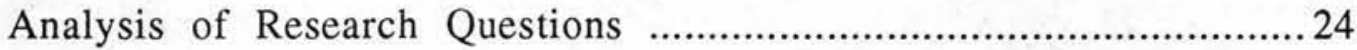

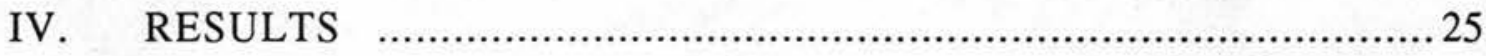

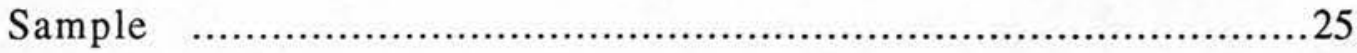

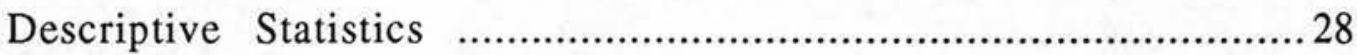

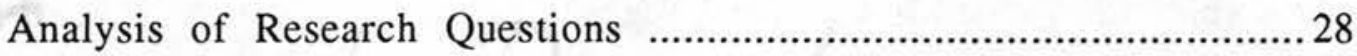

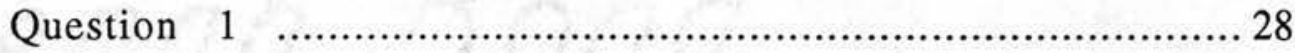

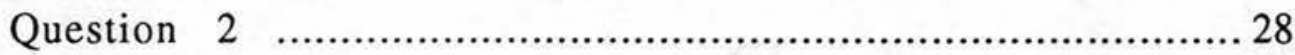

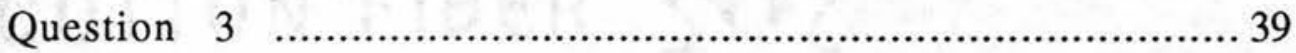

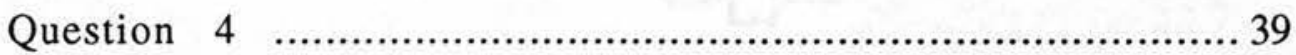

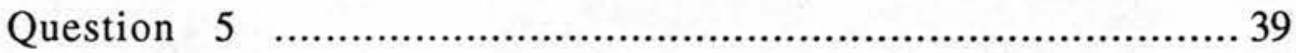

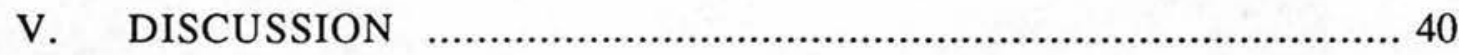

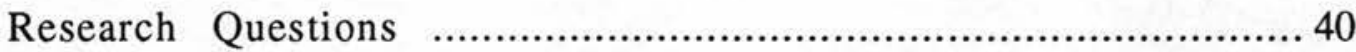

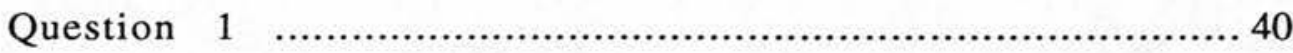

Patient-perceived quality global and patient-perceived quality total ...... 40

Patient-perceived quality and patient goal achievement ..................... 40

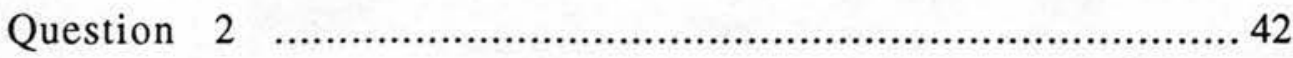


Patient goal achievement and patient goal achievement for pain .42

Patient value and patient beneficence ........................................ 43

Patient value and diminished pain intensity score .......................... 44

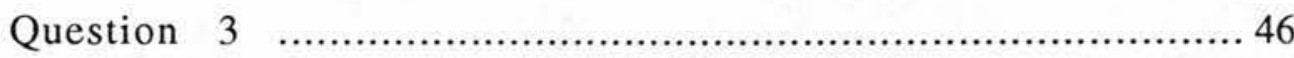

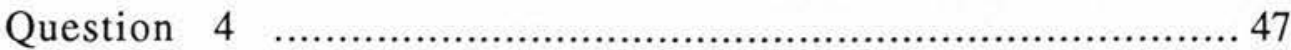

Patient-perceived quality and nurse-perceived quality for pain ........... 47

Patient-perceived quality and nurse-perceived quality for interventions

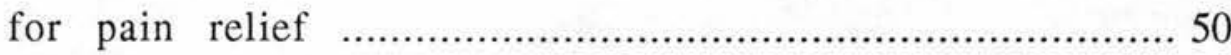

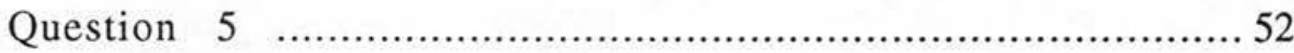

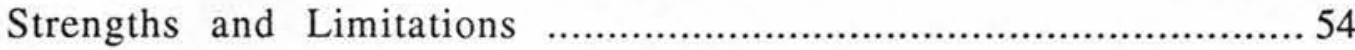

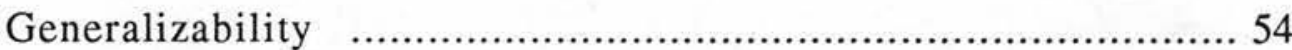

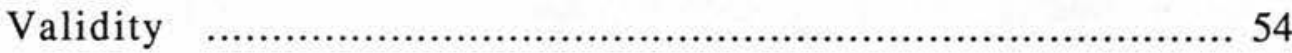

Measurement in Future Research ................................................... 55

Future Research Questions ......................................................... 55

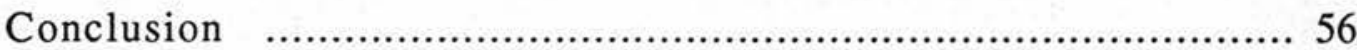

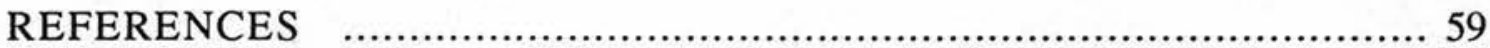

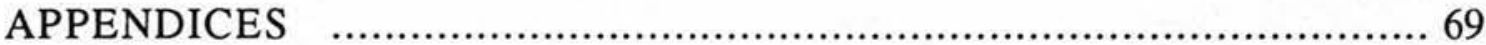

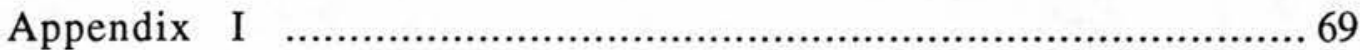

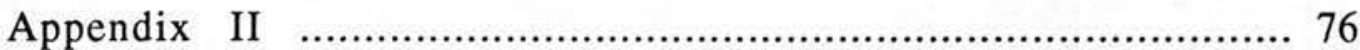

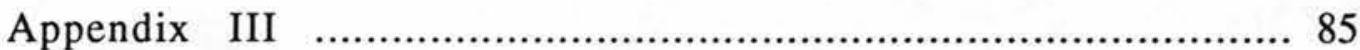

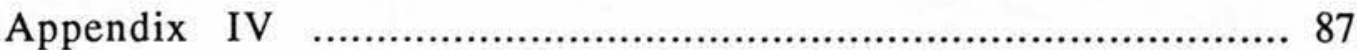

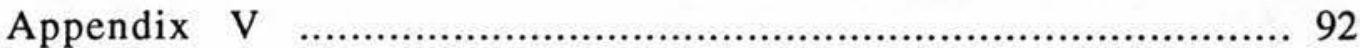

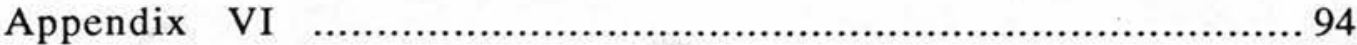

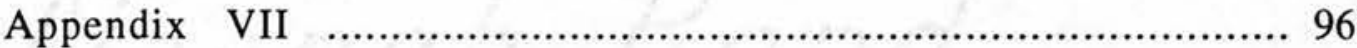

VITA 


\section{LIST OF TABLES}

TABLE

PAGE

1. Patient and Nurse Variables .................................................... 20

2. Comparison of Original Sample to Study Sample ............................... 26

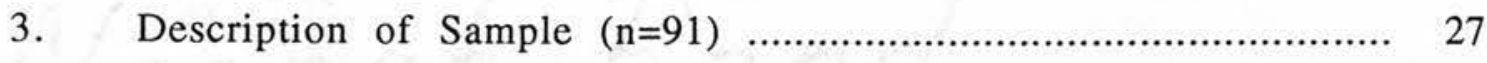

4. Descriptive Statistics for Patient Quality Variables and Nurse Quality

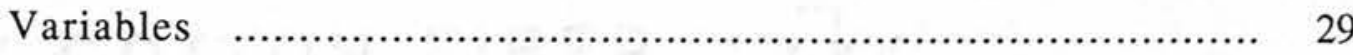

5. Estimated Spearman's correlations Among Patient Quality Variables and Nurse Quality Variables $(n=91)$ 


\section{LIST OF FIGURES}

FIGURE

PAGE

1. Larrabee's Model of Quality ...................................................... 6

2. Model of Investigation …………........................................... 8

3. Distribution of Patient-Perceived Quality Global ……….................... 30

4. Distribution of Patient-Perceived Quality Total …….......................... 31

5. Distribution of Patient Goal Achievement ...................................... 32

6. Distribution of Patient Goal Achievement for Pain .............................. 33

7. Distribution of Diminished Pain Intensity Score ............................... 34

8. Distribution of Nurse-Perceived Quality for Pain ............................... 35

9. Distribution of Nurse Goal Achievement for pain ............................. 36

10. Distribution of Nurse-Perceived Quality Score for Interventions for pain relief 


\section{CHAPTER I}

\section{INTRODUCTION}

Pain is probably the most common and compelling reason why a person seeks medical assistance (Bonica, 1990; McCaffery \& Beebe, 1989). Each year pain disables approximately 50 million Americans (Bonica, 1990). These patients seek health care for the relief of pain and it's underlying cause.

Many of those seeking relief from pain are hospitalized. While others experience pain from surgery, treatments, and procedures during their hospitalization. These patients have the right to relief of their pain and none should suffer pain needlessly. The nursing profession has an obligation to accurately assess the patient's pain, believe the patient's description of that pain, manage the pain within the limitations of the doctor's order, and to function as a patient advocate if pain continues despite treatment (Howard-Ruben \& McGuire, 1990; McCaffery, 1981). Often nurses fail to accurately assess and adequately manage a patient's pain (Bond \& Pilowsky, 1966; Carr, 1990; Choiniere, Melzack, Girand, Rhondeau, \& Paquin, 1990; Cohen, 1980; Donovan, Dillon, \& McGuire, 1987; Dudley \& Holm; 1984; Favaloro \& Touzel, 1990; Fox, 1982; Marks \& Sachar, 1984; McCaffery \& Ferrell, 1991; Melzack, 1990; Puntillo, 1990; Rankin \& Snider, 1984; Winefield, Katsikitis, Hart, \& Rounsefell, 1990).

Nursing executives are facing a combination of factors that make effective pain management a key focus in quality improvement efforts. These factors include the dramatic increase in competition among health care providers (Abramowitz, Cote \& Berry, 1987; Brown, 1992; Eastaugh, 1992; Marker, 1989; Merry, 1987; Meterko, Nelson, \& Rubin, 1990; Prehn, Mayo, \& Weisman, 1989; Reichheld \& Sasser, 1990; Stamps \& Lapriore, 1987; Taylor \& Haussmann, 1988), increases in the consumer expectation of quality (Bader, 1988; Brown, 1992; Ferrell, Wisdom, Rhiner, Alletto, 1991; Merry, 1987; 
Omachonu, 1990; Taylor \& Haussmann, 1988), the need to contain cost while maintaining or improving quality (Consumer Reports, 1992; Feldstein, 1988; Weisbrod, 1985), and the relationship between pain and the patient's perception of quality (Larrabee, 1992). The patient's perception of quality has been shown to influence patients' overall satisfaction and the patient's intent to return or recommend (Doering, 1983; Meterko, Nelson, \& Rubin, 1990; Stamps \& Lapriore, 1987). In addition, patient dissatisfaction has been shown to influence patient's intent to sue (Marker, 1989). Studies have also shown a relationship between pain and the patient's and family's overall perception of health care quality (Hull, 1989) and perceptions of nursing care quality (Larrabee, 1992). The nurse executive has a strong economic incentive to examine pain management from patients' and nurses' perspectives, because the adequate treatment of pain may increase patients' perceptions of quality care, increase retention of patients, and decrease liability losses.

\section{Purpose of the Study}

The purpose of this study is to determine the relationships between pain relief and patients' perception and nurses' perception of nursing care quality. These relationships represent the underlying relationship between beneficence and value, as described in Larrabee's model of quality (Larrabee, 1992). Larrabee's Model of Quality and the relationship of these variables are discussed in the conceptual framework section.

\section{Justification for the Study}

The study of patients' and nurses' perception of the quality of pain management is important because adequate pain management will prevent needless suffering of the patient. Adequate pain management may also increase patient perception of nursing care quality. Prevention of the needless suffering of many hospitalized patients is the ultimate goal of all nursing executives. However, increasing patient perception of quality is an important secondary goal for providers in today's health care market place (Abramowitz, Cote \& 
Berry, 1987; Bader, 1988; Brown, 1992; Eastaugh, 1992; Ferrell, Wisdom, Rhiner, Alletto, 1991; Marker, 1989; Merry, 1987; Meterko, Nelson, \& Rubin, 1990; Omachonu, 1990; Prehn, Mayo, \& Weisman, 1989; Reichheld \& Sasser, 1990; Stamps \& Lapriore, 1987; Taylor \& Haussmann, 1988). The quality of pain management is especially meaningful to hospitalized patients and nursing executives because approximately threefourths of the patients admitted to a hospital suffer from moderate to severe pain (Marks \& Sachar, 1980). Yet, nurses very often do not accurately assess or adequately manage patients' pain (Bond \& Pilowsky, 1966; Carr, 1990; Choiniere, Melzack, Girand, Rhondeau, \& Paquin, 1990; Cohen, 1980; Donovan, Dillon, \& McGuire, 1987; Dudley \& Holm; 1984; Favaloro \& Touzel, 1990; Fox, 1982; Marks \& Sachar, 1984; McCaffery \& Ferrell, 1991; Melzack, 1990; Puntillo, 1990; Rankin \& Snider, 1984; Winefield, Katsikitis, Hart, \& Rounsefell, 1990). In fact, several studies have shown that nurses often do not assess the patient's pain, but only respond to the patient's request for pain medication (Carr, 1990; Donovan, Dillon, \& McGuire, 1987; Winefield, Katsikitis, Hart, \& Rounsefell, 1990). Also, nurses do not routinely document the patient's pain or include pain management in the nursing plan of care (Donovan, Dillon, \& McGuire, 1987). Does this inadequate treatment of pain lead to a decrease in patients' perception of the quality of their nursing care?

The relationship between the adequate treatment of pain and patients' perceptions of quality has not been examined, although one study examined the relationship between severity of pain on exit interview and patient's perceptions of quality and found an inverse relationship (Larrabee, 1992). No studies have looked at the relationship between patients' perception of nursing care quality and difference in their pain at initial interview and exit interview. Second, no studies have examined the relationship between the patient's perception of quality nursing care and nurse-perceived quality specific to pain. This study examined these relationships. 
A high level of patient perception of quality is relevant to nursing executives because of the rapidly increasing cost of health care (Consumer Reports, 1992; Feldstein, 1988). These increasing costs have escalated competition among health care providers (Abramowitz, Cote \& Berry, 1987; Brown, 1992; Eastaugh, 1992; Marker, 1989; Merry, 1987; Meterko, Nelson, \& Rubin, 1990; Prehn, Mayo, \& Weisman, 1989; Reichheld \& Sasser, 1990; Stamps \& Lapriore, 1987; Taylor \& Haussmann, 1988) and have lead to increased consumer expectations (Bader, 1988; Brown, 1992; Ferrell, Wisdom, Rhiner, Alletto, 1991; Merry, 1987; Omachonu, 1990; Taylor \& Haussmann, 1988) regarding the quality of their care. Thus, both increased competition and consumer expectations have ignited a fervent search by nursing executives for the competitive edge and avenues to better meet consumer expectations. This search has lead to an intensive effort to understand patient satisfaction through use of surveys. Several of these surveys have linked patient satisfaction directly to the patient intent to recommend and to return to the hospital (Doering, 1983; Meterko, Nelson, \& Rubin, 1990; Stamps \& Lapriore, 1987). It has also been demonstrated that patient dissatisfaction is linked with intent to sue (Marker, 1989).

These findings represent strong economic incentives because they suggest that retention of patients by nursing executives and avoidance of law suits is based upon providing quality care that is satisfying to the patient. Providing quality, satisfying health care must begin with quality, satisfying nursing care. Satisfaction with nursing care is relevant, because many studies have shown a high correlation between satisfaction with nursing care and satisfaction with overall care (Abramowitz, Cote \& Berry, 1987; Fleming, 1981; Steiber, 1989; Walker \& Restuccia, 1984). In other words, as the patient's perception of nursing care quality is increased, the satisfaction with overall health care is also increased.

In summary, pain has been demonstrated to be inversely related to patient 
perception of nursing care quality (Larrabee, 1992) and to hospital care quality (Meterko, Nelson, \& Rubin, 1990). Patient perception of nursing care quality has been demonstrated to be a major predictor of patient perception of hospital care quality (Abramowitz, Cote \& Berry, 1987; Fleming, 1981; Steiber, 1989; Walker \& Restuccia, 1984), and patient perception of hospital care quality has been demonstrated to be associated with patient intent to recommend and return to a hospital (Doering, 1983; Meterko, Nelson, \& Rubin, 1990; Stamps \& Lapriore, 1987). Thus, providers have both humanitarian and economic motives to learn more about pain and its treatment from both patients' and nurses' perspectives. Does adequate treatment of pain have a positive correlation with the patient's perception of the quality of nursing care? If there is a relationship, the adequate treatment of pain could increase overall patient satisfaction with health care.

\section{Conceptual Framework}

The conceptual framework for this study is Larrabee's model of quality, a wholistic model of quality (Larrabee, 1992), see Figure 1. This model is an appropriate framework for investigation of the relationship between patient perceptions of quality of care, patient values, provider values, and patient behavioral outcomes, because of the model's wholistic nature.

\section{Overview of the Conceptual Framework}

In Larrabee's model of quality, quality is defined as the "presence of socially acceptable, desired attributes within the multifaceted wholistic experience of being and doing and quality encompasses at least the four interrelated concepts: value, beneficence, prudence, and justice", see Figure 1 (Larrabee, 1992, p. 17). These concepts are defined as follows:

Value is defined as: (a) something intrinsically desirable; (b) relative worth, utility, or importance; and (c) a fair return in goods, services, or money for something 


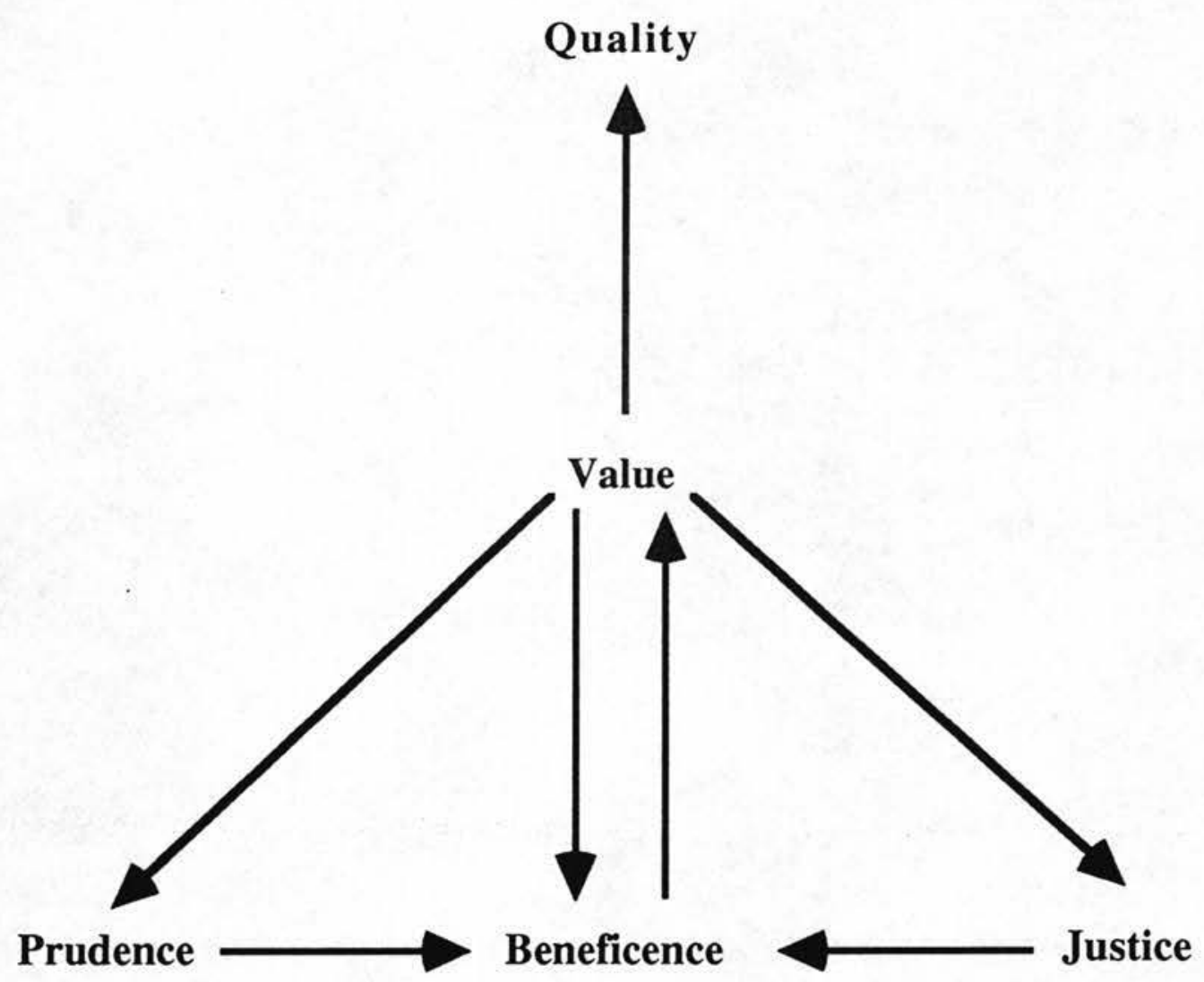

Figure 1. Larrabee's model of quality.

From "Hospital Patients and Nurses Perceptions of Quality" by J. H. Larrabee 1992, unpublished doctoral dissertation, The University of Tennessee, Memphis. Reprinted with permission of the author. 
exchanged. Beneficence, is defined as actual or potential capability for (a) producing good and (b) promoting well-being. Prudence is defined as: (a) good judgment in setting realistic goals and (b) good judgment and skill in using personal resources to achieve goals. Justice is defined as fairness, which has these two components: (a) distributive justice, using common resources proportionately to the individual's contribution to those resources and (b) corrective justice, correcting an injustice by finding the means between the extremes of profit and loss. (Larrabee, 1992, p.17)

Each of the concepts is related to each other and all are related to quality. The proposed relationship of model concepts suggests that the more patients value something, the higher their expectations of the quality of that thing and the more likely they are to expend personal resources (prudence) to have or achieve it. Similarly, the more society values the benefits of this thing, the more likely they are to expend public resources (justice) in its pursuit and the higher societal expectations of the quality of this thing. Therefore, value is proposed as intervening between quality and the remaining model concepts (Larrabee, 1992).

\section{Operationalization of the Concepts}

This study examined the relationships between quality, value, and beneficence specific for patients experiencing pain. These concepts are operationalized as described below (Figure 2). Initial support for relationships between quality and value and quality and beneficence were demonstrated in Larrabee's study (Larrabee, 1992). However, Larrabee's sample included both patients who did have pain, as well as those who did not.

Quality. Quality cannot be measured directly. It must be measured as perceptions or as compliance with a set of pre-existing standards or criteria. This study measured quality as patient-perceived quality (PQUALG and PQUALT), nurse-perceived quality (NQUALP), and nurse-perceived quality for interventions for pain relief (INTERVEN). 


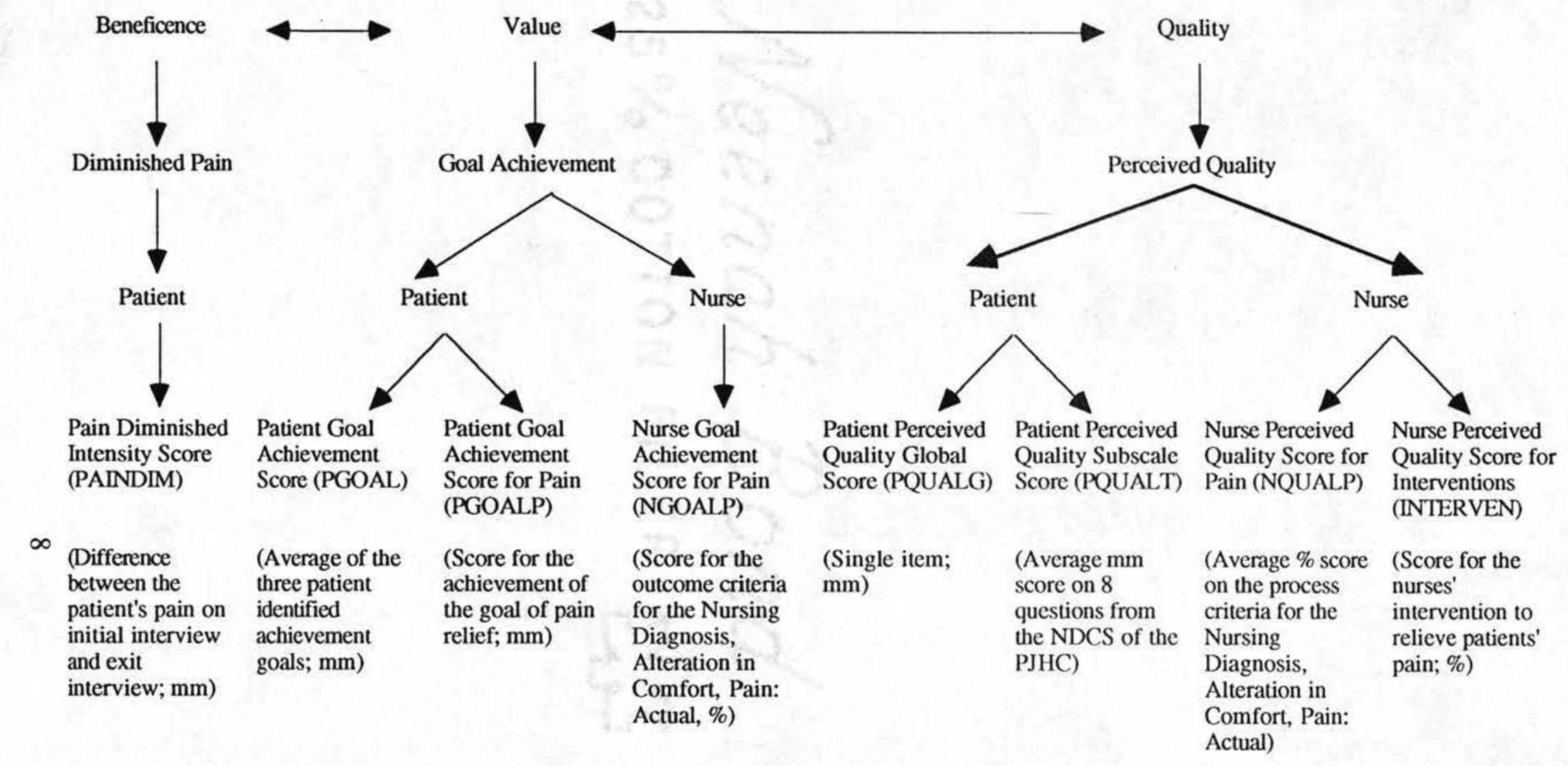

Figure 2. Model for Investigation.

Modified from "Hospital Patients' and Nurses' Perceptions of Quality" by J. H. Larrabee, 1992, unpublished doctoral dissertation, The University of Tennessee, Memphis. 
Value. Value is operationalized as the patient goal achievement of pain relief (PGOALP), the extent to which the patient perceived the desired outcome for pain to be met. Also, value is operationalized as nurse goal achievement for pain (NGOALP), the extent to which the nursing goals for the patient related to pain relief were achieved. The use of goal achievement for pain as value is supported by its congruence with the Larrabee's three definitions of value. First, the relief of pain has "intrinsic value" (Larrabee, 1992, p.17) to the patient. Second, pain relief has "relative worth, utility, [and] importance" (Larrabee, 1992, p.17) to the patient. Except for the obvious rewards from the relief of pain, a pain-free existence, pain relief is also important to the postoperative surgery patient's recovery, for example, by the prevention of pneumonia (Sydow, 1989). Lastly, pain relief does provide a "fair return in goods, services, or money exchanged" (Larrabee, 1992, p. 17), because the effective treatment of pain has proven to decrease patients' hospital stay (Jackson, 1989; Wasylak, Abbott, English, \& Jeans, 1990).

Beneficence. Beneficence is operationalized as the diminished intensity of pain between the time of the initial interview and the time of the exit interview (PAINDIM). The use of diminished intensity in pain at initial interview and exit interview is supported by the definition of beneficence in Larrabee's model of quality (Larrabee, 1992). Diminishing pain, when it represents relief, is "promoting good" and "promoting well-being" for the patient (Larrabee, 1992, p. 17). Thus, beneficence is accomplished through decreasing patient suffering, preventing patient complications (Sydow, 1989), and speeding patient recovery (Jackson, 1989; Wasylak, Abbott, English, \& Jeans, 1990). However, if pain increases, beneficence is not accomplished and patient recovery is impeded (Jackson, 1989; Wasylak, Abbott, English, \& Jeans, 1990).

To explore the relationship between quality, value, and beneficence requires utilization of one of the model's propositions, "when something is potentially beneficial, there is a positive relationship between its value as its relative worth and perception of 
quality" (Larrabee, 1992, p. 134). In other words, this proposed relationship suggests that the greater the perceived benefit (value), the greater the perception of quality.

\section{Summary}

Although initial support for a relationship between quality and value and quality and beneficence was demonstrated in Larrabee's study (Larrabee, 1992), the sample included both patients who did have pain as well as those who did not. No studies have examined the relationships between quality and value and quality and beneficence for an exclusive sample of patients experiencing pain. This study tested the relationships among patient quality, value, and beneficence, proposed in Larrabee's model of quality (Larrabee, 1992) using a sample of patients who reported pain as being their chief complaint upon hospital admission. Also, this study examined the relationship between patient quality and nurse quality and between nurse quality and nurse value.

\section{Research Questions}

The research questions for this study are listed below.

\section{Question 1}

Is there a relationship between patient-perceived quality (PQUALG and PQUALT) and patient value (PGOAL and PGOALP)?

\section{Question 2}

Is there a relationship between patient value (PGOAL and PGOALP) and patient beneficence (PAINDIM)?

\section{Question 3}

Is there a relationship between the patient-perceived quality (PQUALG and PQUALT) and patient beneficence (PAINDIM)? 


\section{Question 4}

Is there a relationship between patient-perceived quality (PQUALG and PQUALT) and nurse-perceived quality for pain (NQUALP) and between the patient-perceived quality (PQUALG and PQUALT) and the nurse-perceived quality score for interventions given for pain relief (INTERVEN)?

\section{Question 5}

Is there a relationship between nurse goal achievement for pain (NGOALP) and the nurse-perceived quality score for interventions given for pain relief (INTERVEN)? 


\section{CHAPTER II}

\section{REVIEW OF LITERATURE}

\section{Pain}

\section{Definition of Pain}

Defining pain is a difficult task, because of the multiple definitions of pain, meanings and the complexity of personal experience. Most dictionaries (Guralnik, 1982) have a number of meanings, as do most leading pain authorities and organizations (American Pain Society, 1989; Bonica, 1990; Loeser \& Cousins, 1990; McCaffery \& Beebe, 1989; U. S. Department of Health and Human Services, 1992). For example, pain is defined by the International Association for the Study of Pain as an "unpleasant sensory and emotional experience associated with actual or potential tissue damage or described in terms of such damage" (American Pain Society, 1989, p.2). In contrast, McCaffery and Ferrell (1991), defined pain as "whatever the experiencing person says it is, existing whenever the experiencing person says it does (p. 7). This definition will be used to define pain in this study. This definition is consistent with the measurement of pain in the original study (Larrabee, 1992).

\section{Overview}

Ironically, little is known about pain, though it has been a major concern of humankind for generations. Man has suffered with this evil since his beginning and has devoted numerous amounts of time and expense to understanding and controlling it. Pain has disabled and distressed more people than any single disease (Bonica, 1990).

The current literature is saturated with articles on pain assessment techniques/tools (Beyer \& Levin, 1987; Broome, Bates, Lillis, \& McGahee, 1990; Cahill, Panzarella, \& Spross, 1990; Houde, 1982; McCaffery \& Beebe, 1989; McGuire, 1984; Melzack, 1987; 
Savedra, Gibbons, Tesler, Ward, \& Wegner, 1982; U.S. Department of Health and Human Services, 1992; Wilkie, Holzemer, Tesler, Ward, Paul, \& Savedra, 1990; Wilkie, Savedra, Holzemer, Tesler, \& Paul, 1990), various pain treatments (Anderson \& Poole, 1983; Baggerly, 1986; Barswick \& Llewellyn, 1982; Beaver, 1980; Bell, Mishra, Weldon, Murray, Calvey, \& Williams, 1985; Bragg, 1989; Caballero, Ausman, \& Himes, 1986; Campbell, Mason, \& Weiler, 1983; Crawled, Lubesnick, \& Sylwestrak, 1991; DiMotto, 1984; Fakouri \& Jones, 1987; Foley, 1985; Foley \& Inturrisi, 1987; Geden, Beck, Hauge, \& Pohlman, 1984; Hansberry, Bannick, \& Durkan, 1990; Hodes, Howland, Lightfoot \& Cleeland, 1990; Keller \& Bzdek, 1986; King, Norsen, Robertson, \& Hicks, 1987; Lamontagne, Mason, \& Hepworth, 1985; Leib \& Hurtig, 1985; Magnani, Johnson, \& Ferrante, 1987; McCaffery \& Beebe, 1989; McGuire \& Wright, 1984; Melzack, 1990; Melzack, Guite, Gonshor, 1980; Miller, 1987; Paice, 1987; Portenoy, Foley, \& Inturrisi, 1990; Smith \& Womack, 1987; Spiegel, 1985; Steward, 1986; Walker \& Katz, 1981; Wells, 1982; White, 1988; Whitman, 1984; Wild, 1990; Wilkie, 1990; Wright, 1987; Ziporyn, 1984), and pain control techniques that can be used for a wide range of ages and medical diagnosis (Anderson \& Poole, 1983; Baggerly, 1986; Barswick \& Llewellyn, 1982; Beaver, 1980; Bell, Mishra, Weldon, Murray, Calvey, \& Williams, 1985; Bragg, 1989; Caballero, Ausman, \& Himes, 1986; Campbell, Mason, \& Weiler, 1983; Crawled, Lubesnick, \& Sylwestrak, 1991; DiMotto, 1984; Dudley \& Holm, 1984; Fakouri \& Jones, 1987; Foley, 1985; Foley \& Inturrisi, 1987; Geden, Beck, Hauge, \& Pohlman, 1984; Hansberry, Bannick, \& Durkan, 1990; Hodes, Howland, Lightfoot \& Cleeland, 1990; Keller \& Bzdek, 1986; King, Norsen, Robertson, \& Hicks, 1987; Lamontagne, Mason, \& Hepworth, 1985; Leib \& Hurtig, 1985; Magnani, Johnson, \& Ferrante, 1987; McCaffery \& Beebe, 1989; McGuire \& Wright, 1984; Melzack, 1990; Melzack, Guite, Gonshor, 1980; Miller, 1987; Paice, 1987; Portenoy, Foley, \& Inturrisi, 1990; Smith \& Womack, 1987; Spiegel, 1985; Steward, 1986; Walker \& Katz, 1981; Wells, 1982; White, 1988; 
Whitman, 1984; Wild, 1990; Wilkie, 1990; Wright, 1987; Ziporyn, 1984). Pain is and should be a major concern of the nursing profession, because nurses spend a greater amount of time with the patient than any other discipline (Bonica, 1990; Bader, 1988). Furthermore, the nurse has major responsibility for the assessment of pain and administration of pain medications.

\section{Pain Assessment}

Assessment is the initial step in the treatment of pain. The nurse's assessment of the patient's pain is crucial to the proper treatment of pain. Yet, nurses very often do not accurately assess or adequately manage pain (Bond \& Pilowsky, 1966; Carr, 1990; Choiniere, Melzack, Girand, Rhondeau, \& Paquin, 1990; Cohen, 1980; Donovan, Dillon, \& McGuire, 1987; Dudley \& Holm; 1984; Favaloro \& Touzel, 1990; Fox, 1982; Marks \& Sachar, 1984; McCaffery \& Ferrell, 1991; Melzack, 1990; Puntillo, 1990; Rankin \& Snider, 1984; Winefield, Katsikitis, Hart, \& Rounsefell, 1990). Several studies have shown that nurses often do not assess the patient's pain, but only respond to the patient's request for pain medication (Carr, 1990; Donovan, Dillon, \& McGuire, 1987; Winefield, Katsikitis, Hart, \& Rounsefell, 1990). For example, one study found that $58 \%$ of medical/surgical patients experienced pain. However, the health care team assessed pain, documented presence of pain, and documented pain assessment for less than half of these patients who reported pain (Donovan, Dillon, \& McGuire, 1987). Another example was described in a study on cancer pain management (Fox, 1982). A patient had an order for "Dilaudid every 4 hours p.r.n.", but despite multiple notations by the physician of the patient's continued pain, the nursing staff only administered the pain medication at 8 to 12 hour intervals. The physician increased the frequency to every 3 hours p.r.n., but the drug continued to be administered at 8 to 12 hour intervals (Fox, 1982).

When nurses do assess patients' pain, they often inaccurately assess the pain for several reasons. First, many nurses utilize behavioral characteristics of pain to assess their 
patients' level of pain (McCaffery \& Beebe, 1989; McCaffery \& Ferrell, 1991; Sanford \& Schlicher, 1986). Eland (1988) described behavioral characteristics of pain as "guarding behavior, narrowed focus, facial mask of pain, diaphoresis, blood pressure, pulse rate change, pupillary dilation, increased respiratory rate, and decreased respiratory rate" (p. 11). However, these pain characteristics are not always present in every patient. Their presence may be affected by a number of factors including the patient's age (Favaloro \& Touzel, 1990; Feldstein, 1988; Frack, 1986; Keefe \& Williams, 1990; Kwentus, Harkins, Lignon, \& Silverman, 1985; Marchette, Main, Redick, Bagg, \& Leatherland, 1991; McCaffery \& Beebe, 1989; Swafford \& Allan, 1968), individual variations (McCaffery \& Beebe, 1989; McCaffery \& Ferrell, 1991), cultural variations (Bonica, 1990; McCaffery \& Beebe, 1989; Villarruel, 1992; Zborowski, 1969), or even distraction from pain (Geden, Beck, Hauge, \& Pohlman, 1984; Hodes, Howland, Lightfoot \& Cleeland, 1990; McCaffery \& Beebe, 1989; McCaffery \& Ferrell, 1991). Therefore, these characteristics cannot reliably be used for pain assessment.

The second reason that nurses inaccurately assess the patient's pain is related to their clinical expertise. A greater difference in nurses' estimations of patients' pain and patients' self reports of pain, was found in inexperienced nurses, than experienced nurses (Choiniere, Melzack, Girand, Rhondeau, \& Paquin, 1990).

The third factor that may influence a nurse's ability to assess pain accurately is the nurse's own past pain experiences (Holm, Cohen, Dudas, Medema, \& Allen, 1989). Those nurses who had experienced great pain themselves or who had someone close to them who had had such an experience, were more sympathetic and their comparison ratings of pain were closer to the self-reports of the patients', than the nurses who had not had pain experiences (Holm, Cohen, Dudas, Medema, \& Allen, 1989).

In summary, in order for nurses to treat the patient's pain, the nurse must first accurately assess that pain. Research indicates that pain is either never assessed or is 
assessed inaccurately for many patients (Bond \& Pilowsky, 1966; Carr, 1990; Choiniere, Melzack, Girand, Rhondeau, \& Paquin, 1990; Donovan, Dillon, \& McGuire, 1987;

Favaloro \& Touzel, 1990; Fox, 1982; Marks \& Sachar, 1984; McCaffery \& Ferrell, 1991; Puntillo, 1990; Rankin \& Snider, 1984). This inaccurate or inadequate assessment of pain leads to inadequate pain management and the patient continues to suffer needlessly.

\section{Quality}

Quality is a multi-faceted, multi-dimensional construct and quality literature contains multiple definitions of quality (Campbell, Grant, Royster, \& Thweatt, 1990; Donabedian, 1991; Donabedian, 1988; Fleming, 1981; Joint Commission Accreditation of Healthcare Organizations, 1992; Larrabee, 1992; Marker, 1989; Omachonu, 1990; Rubin, 1990; Reichheld \& Sasser, 1990; Taylor, Hudson, \& Keeling, 1991; Walker \& Restuccia, 1984). When referring to health care, some authors have suggested that quality cannot be defined (Donabedian, 1991; Donabedian, 1988; Pirsig, 1974). For instance, Donabedian (1991) defined quality as so "diverse in nature that neither a unifying construct nor a single empirical measure could be developed." Defining quality patient care has been equally challenging. Currently, quality patient care is defined by The Joint Commission of Accreditation of Healthcare Organizations (1992) as "the degree to which patient care services increase the probability of desired patient outcomes and reduce the probability of undesired outcomes, given the current state of knowledge" (p. 6).

Omachonu's (1990) stated that, "Quality consists of two interdependent parts: quality in fact and quality in perception"(p. 43). Larrabee (1992) noted that perception is dependent on role, which means that, quality patient care may mean one thing to the health care provider and something different to the patient (Bader, 1988; Brown, 1992; Doering, 1983; Erikson, 1987; Fleming, 1981; Marker, 1989; Merry, 1987; Meterko, Nelson, \& Rubin, 1990; Omachonu, 1990; Rempusheski, Chamberlain, Picard, Ruzanski, \& Collier, 1988; Rubin, 1990; Spitzer, 1988; Stamps \& Lapriore, 1987; Steiber, 1989). Nurses' 
perception of quality has typically been associated with conformance to standards of care or practice standards (Bader, 1988; Brown, 1992; Doering, 1983; Donabedian, 1991; Erikson, 1987; Fleming, 1981; Marker, 1989; Merry, 1987; Meterko, Nelson, \& Rubin, 1990; Omachonu, 1990; Rubin, 1990; Stamps \& Lapriore, 1987). Research has shown patients' perception of quality and/or patient satisfaction with health care are related to hospital amenities (Abramowitz, Cote \& Berry, 1987; Doering, 1983; Fleming, 1981; Stamps \& Lapriore, 1987; Walker \& Restuccia, 1984) and to certain dimensions of nursing care (Abramowitz, Cote \& Berry, 1987; Fleming, 1981; Steiber, 1989; Walker \& Restuccia, 1984). Also, patients' perception of quality and/or patient satisfaction with nursing care has been found to be related to care-comfort activities (Hinshaw \& Atwood, 1982) and severity of pain at exit interview (Larrabee, 1992).

Larrabee's model of quality will be used to define quality (Larrabee, 1992). Other models, which have directed traditional quality assurance activities, have not integrated patient perceptions. Larrabee's model of quality is a wholistic model that views the patient as an integral component of quality assessment activities, thus it can serve as a framework for investigating factors that influence patients' and nurses' perceptions of quality, value, and beneficence. 


\section{CHAPTER III}

\section{METHODOLOGY}

\section{Research Design}

This study, a secondary analysis of Larrabee's data, tests the relationships among quality, value, and beneficence in Larrabee's model of quality (Larrabee, 1992). In the original study (Larrabee, 1992), patient data were collected within 24 hours of admission (see Appendix I) and within 24-48 hours of discharge (see Appendix II). Chart data were collected retrospectively (see Appendix III). Additional chart data were collected to supplement the original data (see Appendix IV). The additional data were used to identify nursing interventions performed when there was evidence that the patient was in pain at the time of the initial interview.

\section{Sample}

The sample included a subset $(\mathrm{N}=91)$ of the 199 patients in the original study (Larrabee, 1992). This subset consists of the patients who reported pain as their chief symptom or reason for coming to the hospital and reported that relief of pain was one of their three goals for hospitalization (Larrabee, 1992). Also, the patient had to have the nursing diagnosis, "Alteration in Comfort, Pain; Actual" included in the plan of care. The original study (Larrabee, 1992) sample consisted of all the patients admitted to two Medical/Surgical units during the eleven weeks of the study, who exhibited the inclusion criteria and agreed to participate. Transferred patients were excluded because their nursing care on other units might influence their perceptions of quality. The inclusion criteria were that the patient had sufficient vision to mark or point to a location on the visual analogue scale (VAS), spoke English, and was at least 18 years old. 


\section{Setting}

The site of this study was a private, not-for-profit 455 bed urban teaching hospital with a public mission, or "safety net" hospital, located in the Mid South. This hospital provides care for the majority of uninsured and underinsured persons in Shelby County, more than 22,000 admissions, more than 200,000 outpatient visits, and $\$ 100$ million in charity and indigent care per year (Larrabee, 1992).

\section{Measurement of Patient and Nurse Variables}

\section{Existing Data}

Patient-perceived quality. (PQUALG, PQUALT). Patient-perceived quality, in the original study (Larrabee, 1992), was measured by a $100 \mathrm{~mm}$ VAS (global score) and by a modified version of the Nursing and Daily Care Subscale of the Patients' Judgments of Hospital Quality Questionnaire (total score) containing 8 questions (Larrabee, 1992) the responses to which were obtained during the exit patient interview. These questions were modified from a valid and reliable instrument, The Patients Judgment of Hospital Quality Questionnaire (PJHQ) by Rubin, Ware, Nelson, and Meterko (1990). The questions were modified to allow for the educational level of the sample, which was anticipated to be lower than Rubin's et al. sample. The original PQUALG and PQUALT scores were used in this study (see Table 1) (Larrabee, 1992).

Patient goal achievement. (PGOAL and PGOALP). Patient goal achievement (PGOAL) was measured in the original study (Larrabee, 1992) as the average of three scores on $100 \mathrm{~mm}$ VASs indicating patient perception of achievement of a maximum of three goals for hospitalization. Patients defined their own goals during the initial interview (Larrabee, 1992). Data for those patients with a goal of pain relief were used in this study, as the measure of patient goal achievement for pain (PGOALP). For comparison purposes, the PGOAL score was included also in analyzing two of the research questions. As the 
Table 1

Patient and Nurse Variables

Variable

Variable Name Data Source Data Type

Patient Quality Variables

Patient perceived quality global

Patient perceived quality total

Patient value variable

Patient goal achievement

Patient goal achievement for pain

Patient beneficence variable

Patient diminished pain

Nurse Quality Variables

Nurse perceived quality for pain

Nurse intervention for pain

Nurse Value Variables

Nurse goal achievement for pain

\section{PQUALG}

PQUALT

Original data

Original data

Ratio

Ratio

PGOAL

Original data

Original data

Ratio

PGOAL

Onginal data

Ratio

PAINDIM Original data Ratio

Patient Demographic Variables

$\begin{array}{lccc}\text { Age } & \text { AGE } & \text { Original data } & \text { Interval } \\ \text { Gender } & \text { GENDER } & \text { Original data } & \text { Nominal } \\ \text { Race } & \text { RACE } & \text { Original data } & \text { Nominal } \\ \text { Marital Status } & \text { MARITAL } & \text { Original data } & \text { Nominal }\end{array}$


patients' PGOAL score increases, the patient's estimation of goal achievement increases.

Pain diminished intensity score. (PAINDIM). Pain diminished intensity score (PAINDIM) was calculated as the difference in $\mathrm{mm}$ between the patient's response to the initial interview question about symptom (pain) severity and the patient's response to the exit interview question about pain intensity, as reported on $100 \mathrm{~mm}$ VASs, for patients having less intensity at the exit interview than the initial interview. The initial interview question (Larrabee, 1992) was, "How bad is your biggest health problem [pain]?" (See Appendix I). The exit interview question was, "About how much pain are you in right now?".

Nurse-perceived quality for pain. (NQUALP). Nurse-perceived quality (NQUAL) in the original study (Larrabee, 1992) was measured as the percentage agreement between process standards of care selected for each patient and the nursing care documented for a maximum of three nursing diagnoses per patient. The higher the score, the closer the congruence between the nursing care standards and the nursing care documented. These data were collected by chart review. In this study, only the score for nurse-perceived quality for pain (NQUALP) was used. NQUALP was measured as the percentage agreement between process standards selected for each patient and the nursing care documented for the nursing diagnosis, "Alteration in Comfort, Pain: Actual". For some patients, the nursing diagnosis "Alteration in Comfort, Pain: Actual" was not in the top three nursing diagnoses in the plan of care. Therefore, the data needed for NQUALP were not collected in the original study, but were collected for this study.

Nurse goal achievement for pain. (NGOALP). Nurse goal achievement (NGOAL) in the original study (Larrabee, 1992) was measured as the percentage agreement between outcome standards selected for each patient and outcomes documented for a maximum of three nursing diagnoses. These data were collected by chart review. In this study, only the score for nurse goal achievement for pain (NGOALP) was used. NGOALP was measured 
as the percentage agreement between outcome standards selected for each patient and outcomes documented for the nursing diagnosis, "Alteration in Comfort, Pain: Actual". For some patients, the nursing diagnosis, "Alteration in Comfort, Pain: Actual" was not in the top three nursing diagnoses in the plan of care. Therefore, the data needed for NQUALP were not collected in the original study, but were collected for this study.

\section{New Data}

Nurse-perceived quality for interventions for pain relief (INTERVEN) was measured as the percentage agreement between the number of times the patient was in pain and the number of times the nurse performed an intervention within 30 minutes to relieve the patient's pain. These data were collected by chart review.

\section{Procedure}

The additional data were collected by retrospective chart review. A list of the medical record numbers for the sample was submitted to the Assistant Director of the Medical Records department who arranged for chart retrieval. The investigator collected the new data for Nurse-perceived Quality for Pain (NQUALP) and Nurse Goal Achievement for Pain (NGOALP). The new data were added to the existing data set on EXCEL ${ }^{T M}$ for statistical analysis. The time for data collection was one month with a total of 13.75 hours of chart review time.

\section{Assumptions}

The major assumption for this study, a secondary analysis, was that relief of pain is of value and benefit or beneficial to the patient. Other assumptions include those of the original study (Larrabee, 1992):

1. the patient-perceived quality subscale score and patient-perceived quality global score accurately estimate the patient perceptions of the quality of nursing care they received during hospitalization. 
2. the patient goal achievement score accurately estimates patient perceptions of the extent to which their goals for hospitalization were achieved.

3. the nurse-perceived quality score accurately measures the congruence between nursing care standards and the nursing care given.

4. the nurse-perceived quality score accurately measures the nursing care given.

5. the nurse goal achievement score accurately estimates the extent to which the patient achieved the nurse goals for the patient outcomes.

6. patient can distinguish between care given by nursing staff and care given by other hospital staff.

7. nurses accurately assess patients and select appropriate nursing diagnoses when planning nursing care.

8. nurses' use of the nursing process facilitates achievement of desired outcomes for patients.

\section{Limitations}

Since all additional data collected were obtained by chart review, the major limitation of this study is the availability of the information. The data in the chart are limited to the nursing care documented, which may or may not be equivalent to the nursing care actually given. Additionally, the limitations include those of the original study (Larrabee, 1992):

1. No standardized instrument has been developed for measuring patient goal achievement, nurse goal achievement, or nurse-perceived quality as defined in the original study.

2. VAS has not previously been tested in a predominately black population, although Larrabee (1992) reported no difficulty in patient use of the response scale based on race. 
3. The findings are not generalizable to the population as a whole, because the sample was not representative due to an increased ratio of blacks to whites in the sample, but may be generalizable to other safety-net hospitals.

\section{Protection of Human Subjects}

Institutional Review Board (IRB) approval was obtained before the start of the study. No consent form was used for this secondary analysis of data, but materials were kept in strict confidence and confidentiality maintained.

\section{Analysis of Research Questions}

All of the analysis, except for the F-test for age variance between original and study participants, was performed on the Statistical Analysis System (SAS) software, version six. SAS is available at the UT Bit Center, VAX cluster. The descriptive analyses, including mean, standard deviation, and range for each of the variables, were determined using "proc univariate" in SAS (SAS Institute, 1990; SAS Institute, 1989). Each of the relationships between variables in each of the five questions were determined through Spearman's correlation coefficient, using "proc corr Spearman" in SAS (SAS Institute, 1990; SAS Institute, 1989). Spearman's coefficient was used because the patient and nurse variables were not normally distributed (Rosner, 1990). A nontraditional significance level of .10 was used because these variables have not been previously tested and represent theory testing data (Larrabee, 1992). 


\section{CHAPTER IV}

\section{RESULTS}

\section{Sample}

The sample consists of 91 of the 199 participants of the original study (Larrabee, 1992). Data for all of the original subjects who met the new inclusion criteria were included except for one subject. This subject was excluded because the medical record was missing.

The characteristics gender, race, marital status, and age were analyzed for differences between the original participants and this study's participants. There were no differences on the basis of gender, race, or marital status between the original study's participants and this study's participants, as evaluated by chi-square for variance (see Table 2). Fisher's exact test also indicated non-significance for race and marital status. Fisher's exact test was the preferred test for race and marital status because these characteristics contained cells with a sample less than 5 (Rosner, 1990). Age was evaluated by a F-test for variance (see Table 2), which indicated non-significance. The F-test was the preferred test because the samples were unbalanced (Rosner, 1990). Therefore, there were essentially no differences between the 108 patients excluded and the 91 patients included in the study. The Fisher's exact test and chi-square were performed in SAS, while the F-test was performed on Excel $^{\mathrm{TM}}$.

The sample ( $\mathrm{n}=91$ ) included 46 males and 45 females (see Table 3). Also, the sample was predominately black $(85.7 \%)$, single $(57.1 \%)$, and had less than a high school education $(50.5 \%$ ) (see Table 3 ). The sample reported a mean of 10.5 years of education, with a mode of 12 years (see Table 3). Secondly, the sample had a mean age of 35.5 years, with a mode of 24 years (see Table 3). 
Table 2

Comparison of Original Sample to Study Sample

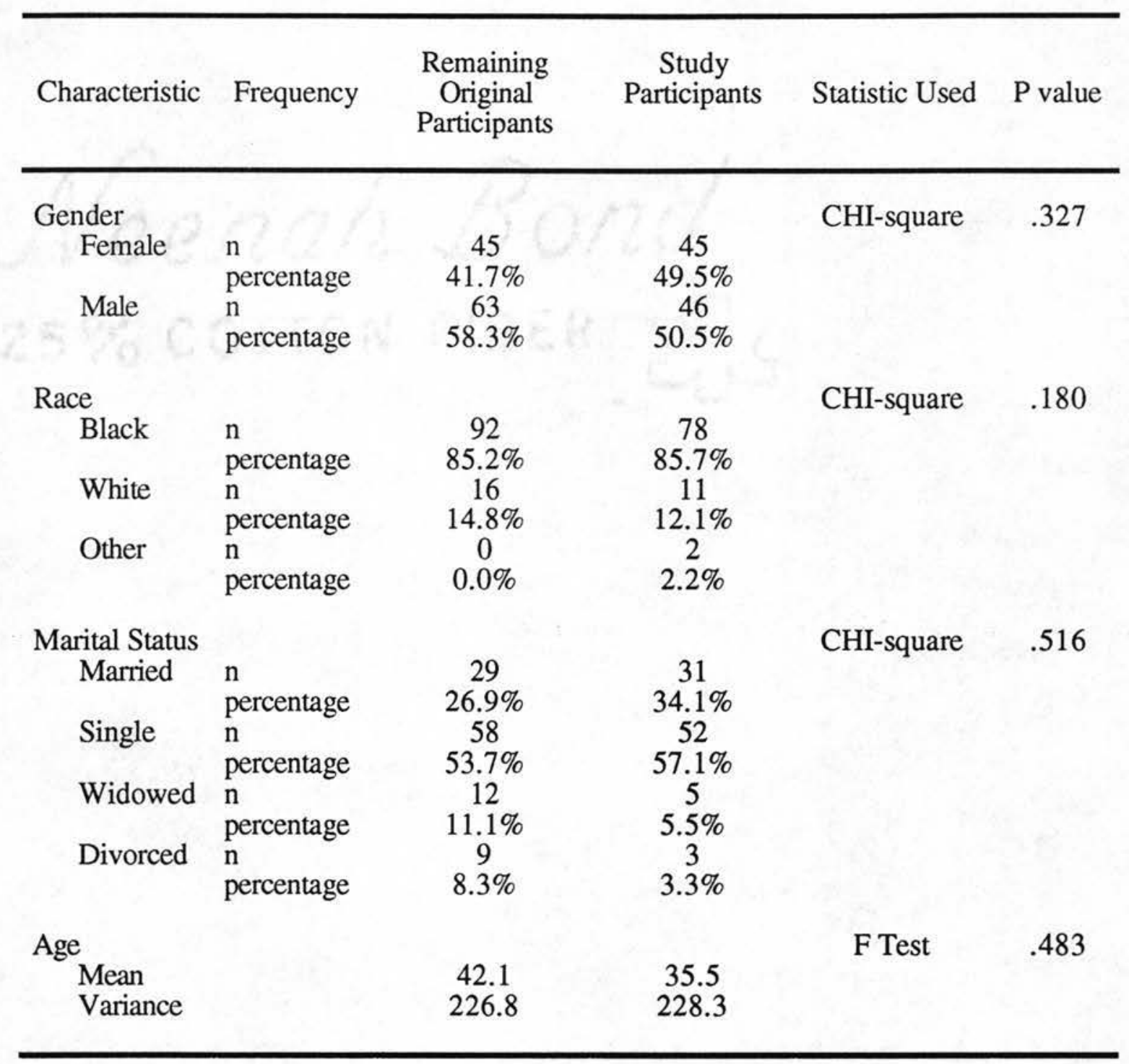


Table 3

Description of Sample ( $n=91$ )

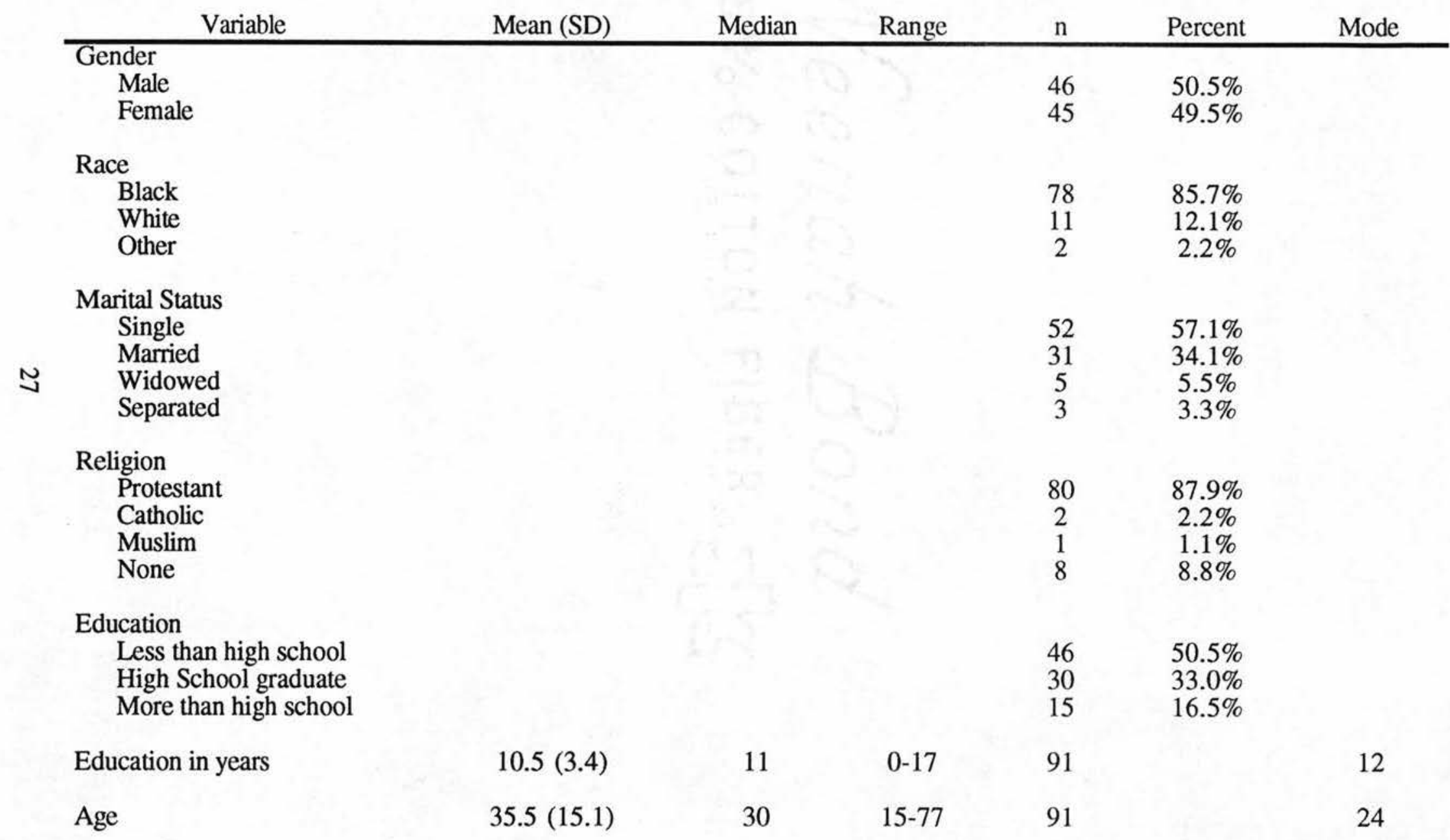




\section{Descriptive Statistics}

Descriptive statistics for the patient quality variables (PQUALG, PQUALT, PGOAL, PGOALP, and PAINDIM) and nurse quality variables (NQUALP, NGOALP, and INTERVEN) are displayed in Table 4. The distributions of these variables are shown in Figures 3 - 10. Because none of the patient or nurse variables were normally distributed, analyses of the research questions were conducted using Spearman's correlation coefficient (Rosner, 1990).

\section{Analysis of Research Questions}

\section{Question 1: Is there a relationship between patient-perceived quality} (PQUALG and PQUALT) and patient value (PGOAL and PGOALP)?

First, there was a significant positive relationship between patient-perceived quality global (PQUALG) and patient-perceived quality total (PQUALT) (see Table 5). Second, a significant positive relationship between patient-perceived quality (PQUALG and PQUALT) and patient goal achievement (PGOAL) was noted (see Table 5). Thirdly, a significant positive relationship was shown between patient-perceived quality (PQUALG and PQUALT) and patient goal achievement for pain (PGOALP) (see Table 5).

\section{Question 2: Is there a relationship between patient value (PGOAL and PGOALP) and patient beneficence (PAINDIM)?}

First, patient goal achievement (PGOAL) has a positive significant correlation with patient goal achievement for pain (PGOALP) (see Table 5). A significant positive relationship was shown between patient goal achievement (PGOAL) and patient beneficence (PAINDIM) (see Table 5). However, there was no relationship between patient goal achievement for pain (PGOALP) and patient beneficence (PAINDIM) (see Table 5). 


\section{Table 4}

Descriptive Statistics for Patient Quality Variables and Nurse Quality Variables*

\begin{tabular}{|c|c|c|c|c|c|c|}
\hline \multirow[b]{2}{*}{ Variable } & \multirow[b]{2}{*}{$\mathrm{n}$} & \multirow[b]{2}{*}{ Mean (SD) } & \multicolumn{3}{|c|}{ Quantile } & \multirow[b]{2}{*}{ Mode } \\
\hline & & & $25 \%$ & $50 \%$ & $75 \%$ & \\
\hline \multicolumn{7}{|l|}{ Patient quality variables } \\
\hline Patient perceived quality global & 91 & $80.46(20.69)$ & 67.00 & 89.00 & 97.00 & 100 \\
\hline Patient perceived quality total & 91 & $80.57(18.62)$ & 69.90 & 86.80 & 96.30 & 96.1 \\
\hline Patient goal achievement & 91 & $68.66(22.67)$ & 53.67 & 73.50 & 87.00 & 58 \\
\hline Patient goal achievement for pain & 91 & $71.42(26.81)$ & 53.00 & 79.00 & 95.00 & 100 \\
\hline Diminished pain & 85 & $66.25(27.10)$ & 45.00 & 70.00 & 92.00 & 99 \\
\hline \multicolumn{7}{|l|}{ Nurse quality variables } \\
\hline Nurse perceived quality for pain & 86 & $45.49(25.67)$ & 26.70 & 44.40 & 66.70 & 66.7 \\
\hline Nurse goal achievement for pain & 86 & $90.10(20.27)$ & 88.90 & 100.00 & 100.00 & 100 \\
\hline Nurse interventions for pain & 83 & $78.70(28.23)$ & 66.70 & 90.00 & 100.00 & 100 \\
\hline
\end{tabular}

*Patient variables scored on a $100 \mathrm{~mm}$ visual analogue scales. Nurse variables scored as percent compliance with standards. 


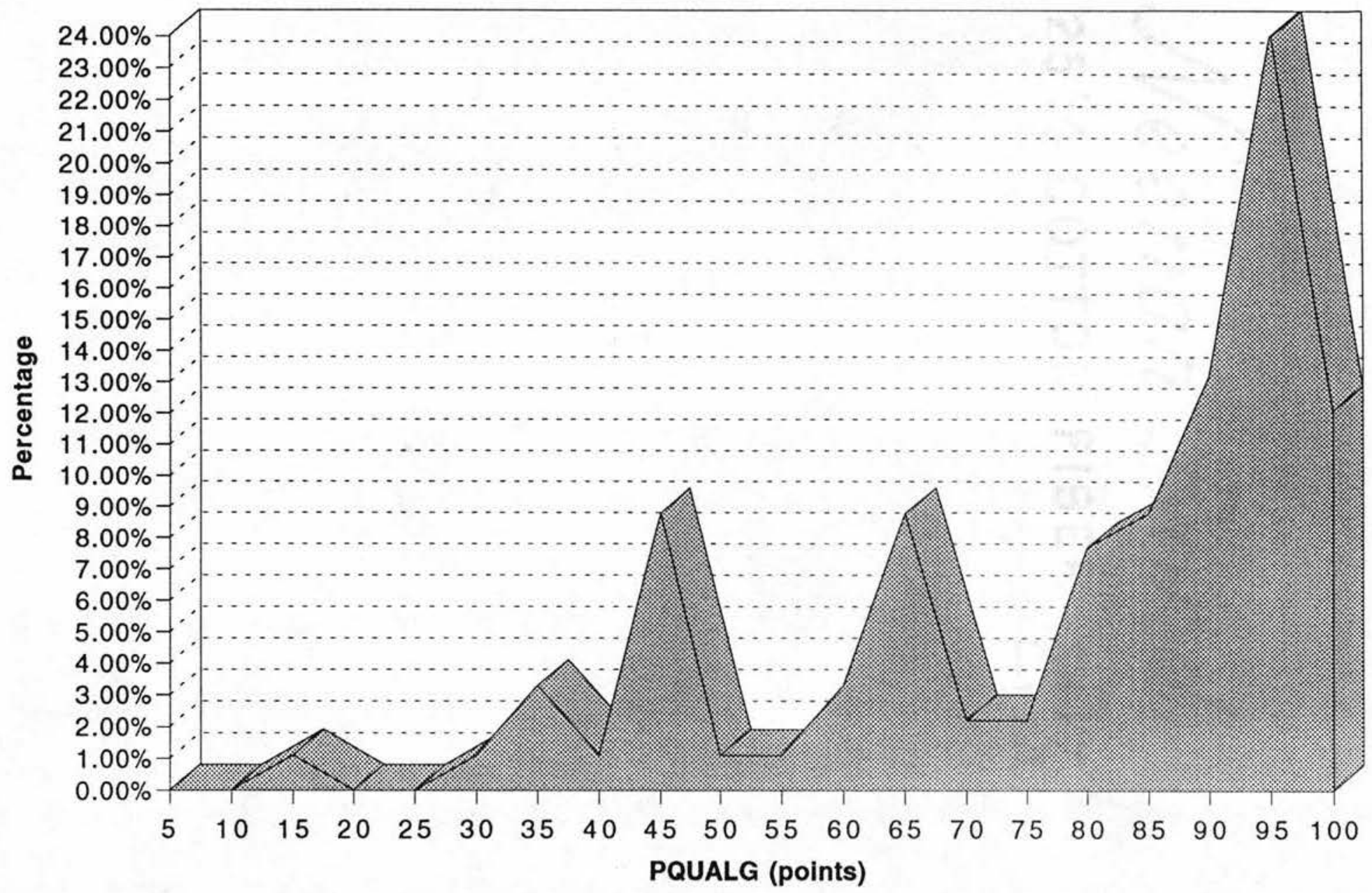

Figure 4. Distribution of patient perceived quality global. 


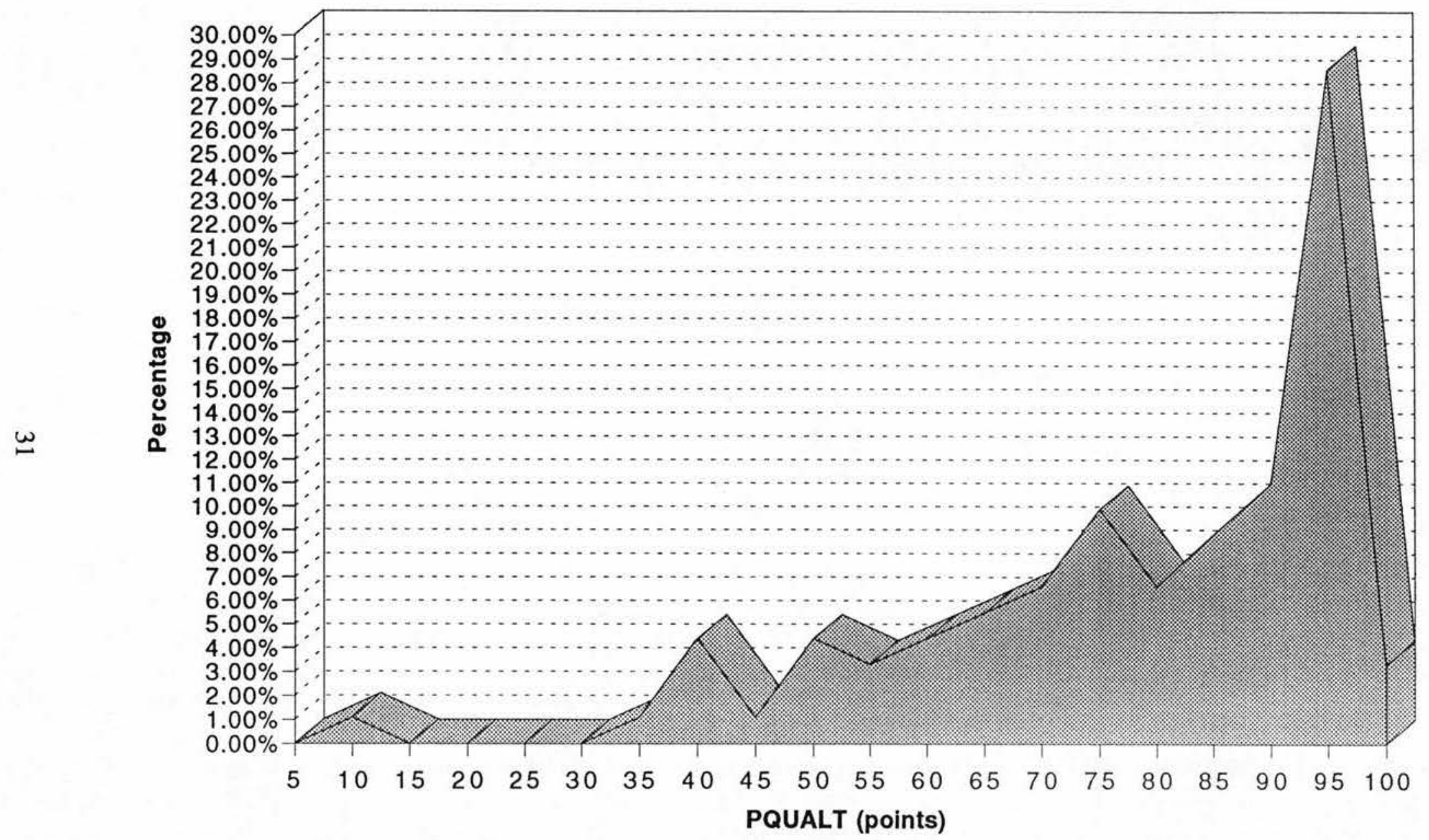

Figure 5. Distribution of patient perceived quality total. 


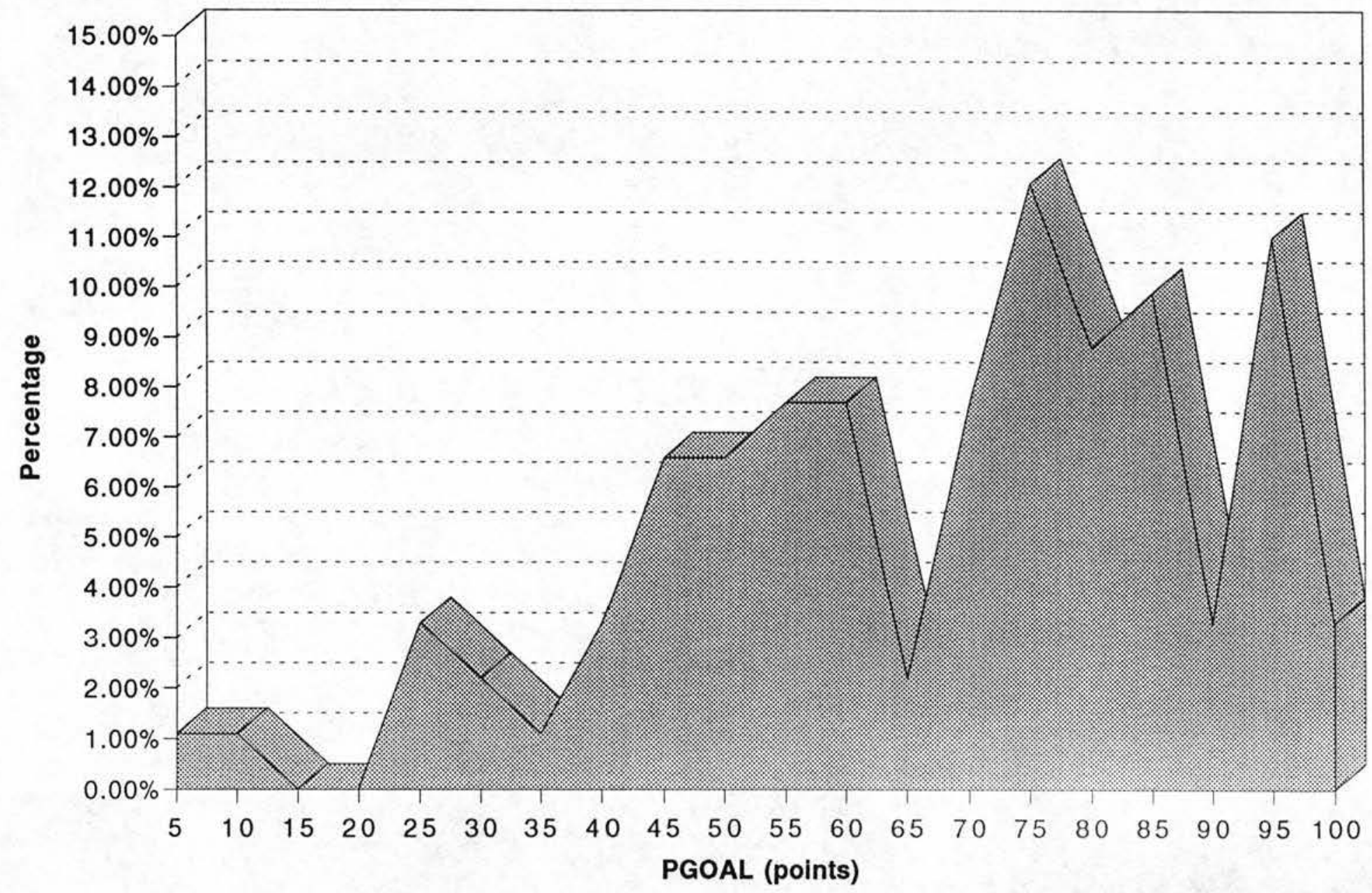

Figure 6. Distribution of patient goal achievement. 


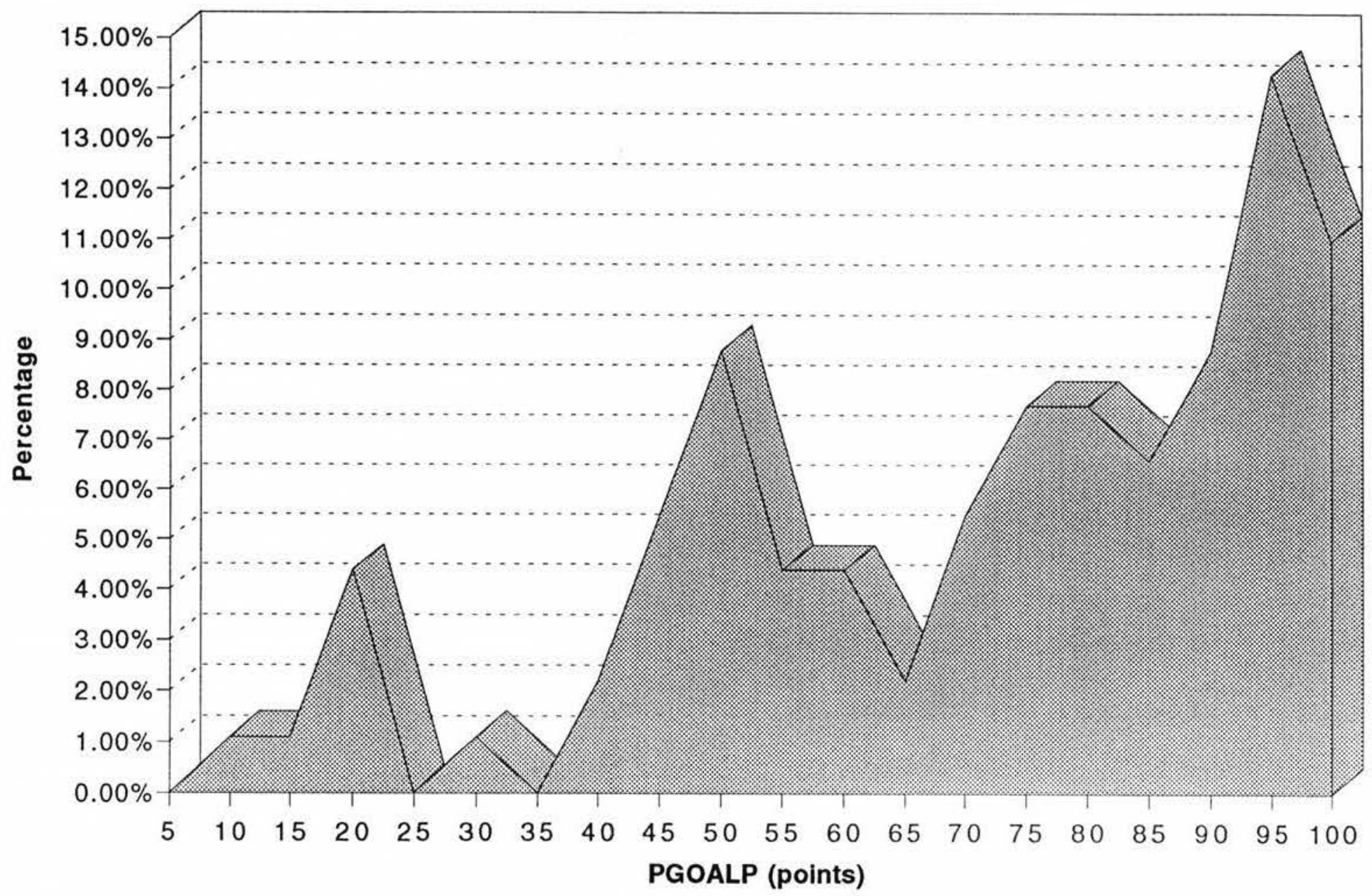

Figure 7. Distribution of patient goal achievement related to pain 


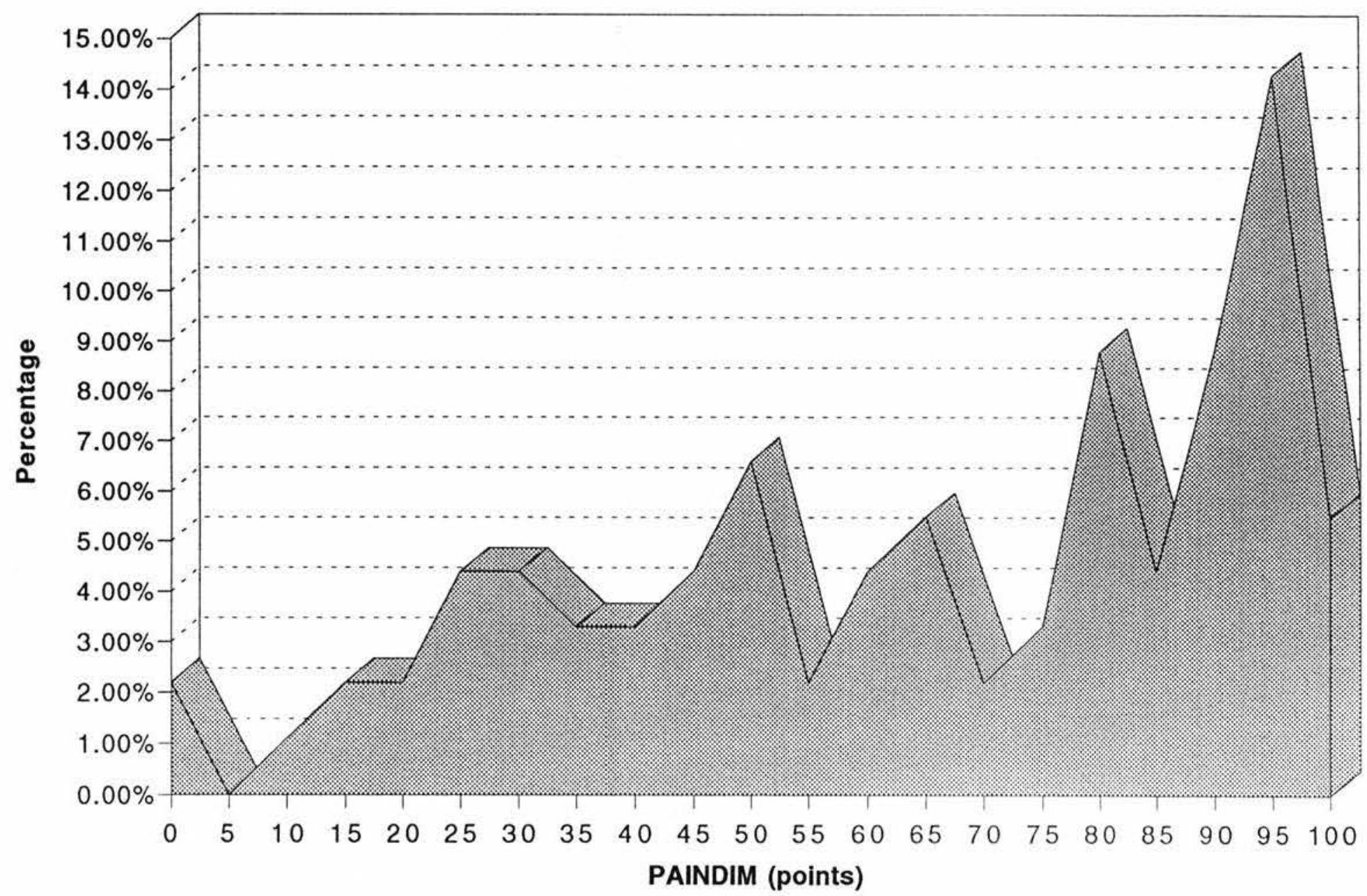

Figure 8. Distribution of the diminished pain intensity score 


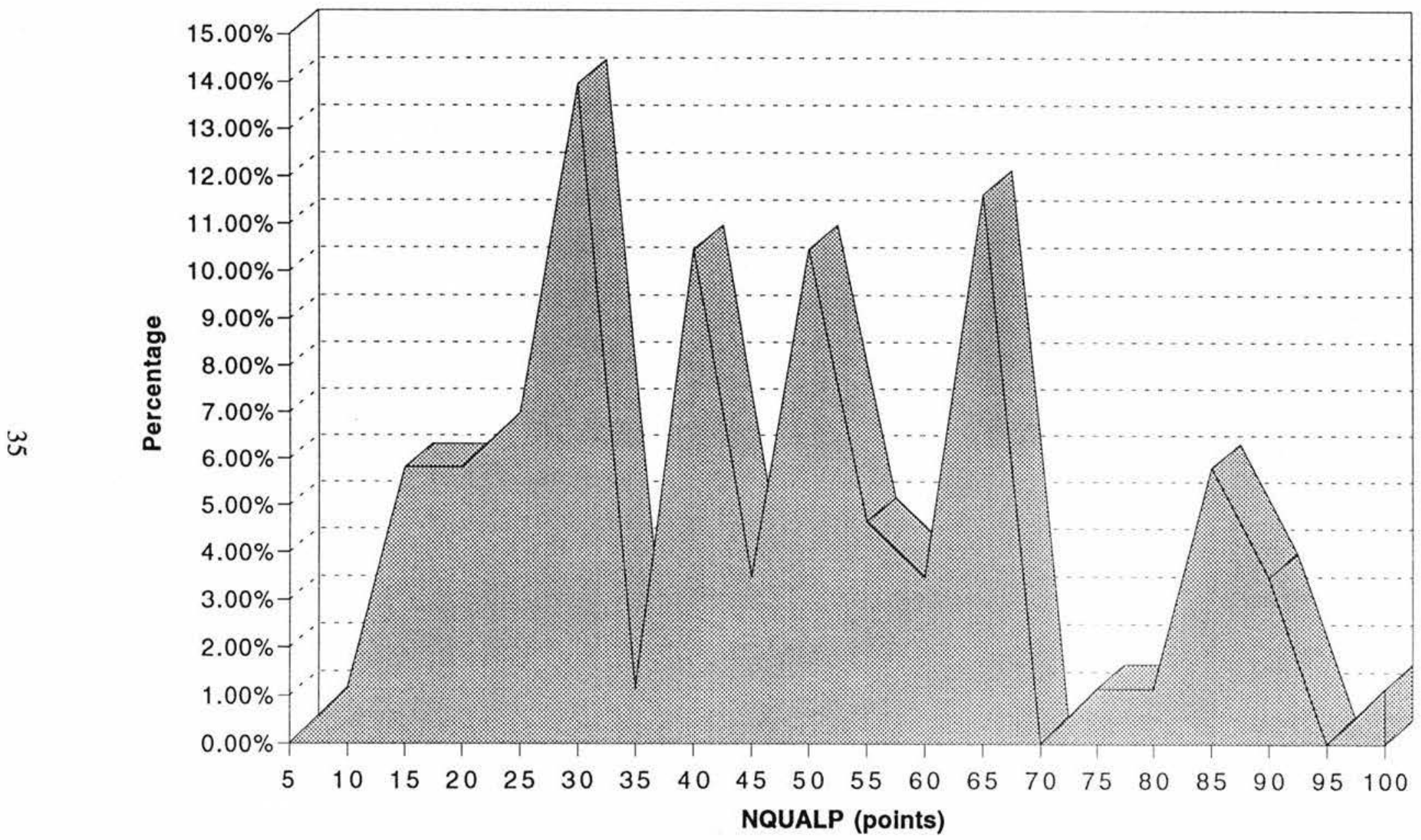

Figure 9. Distribution of the nurse perceived quality for pain 
w

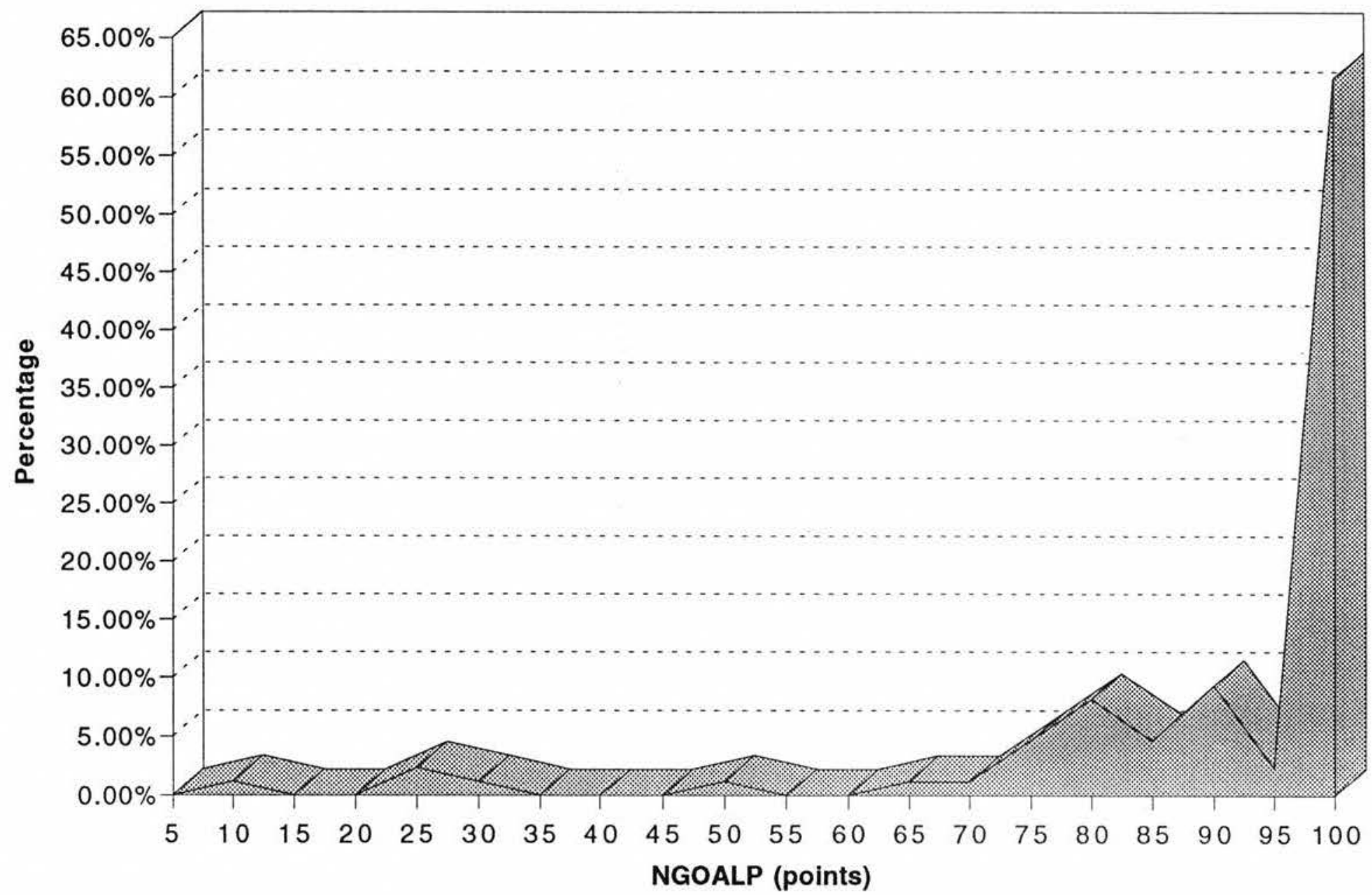

Figure 10. Distribution of nurse goal achievement for pain. 


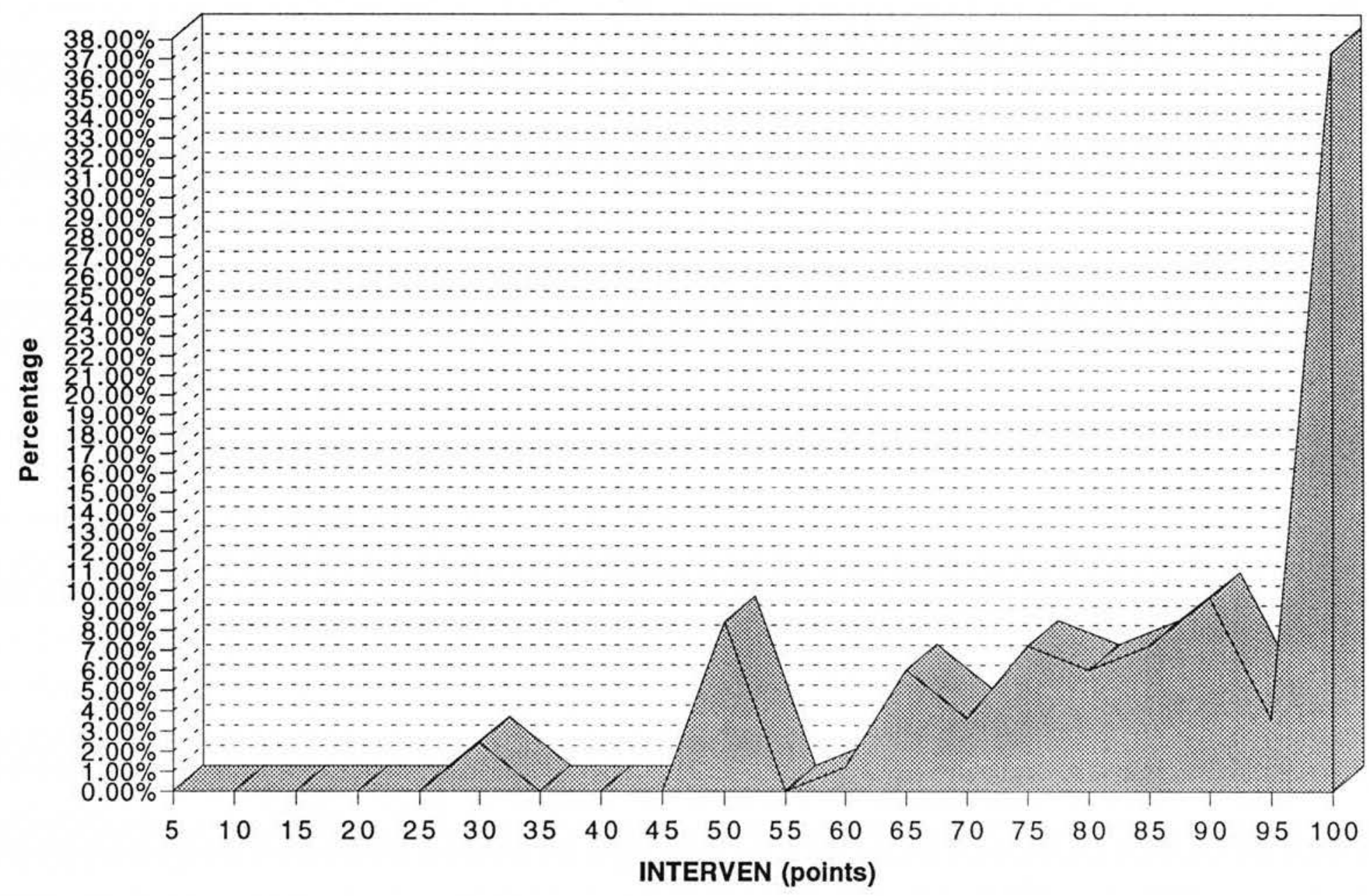

Figure 11. Distribution of the nurse perceived quality score for interventions for pa 
Table 5

Estimated Spearman's Correlations Among Patient Quality Variables and Nurse Quality Variables (n=91)

PQUALG PQUALT PGOAL PGOALP PAINDIM NQUALP NGOALP

\section{Patient quality variables}

Patient perceived quality global (PQUALG)

$\begin{array}{ccccccc} & .79 * * * * * & .31 * * * & .20 * * & .05 & -.08 & .21 * * \\ .79 * * * * * & & .38 * * * * * & .22 * * * & .15 & .05 & .20 * \\ .31 * * * & .38 * * * * * & & .72 * * * * * & .20 * * & .14 & .31 * * * * \\ .20 * * & .22 * * * & .72 * * * * * & & -.05 & -.03 & .18 * \\ .05 & .15 & .20 * * & -.05 & & .04 & .23 * * *\end{array}$

\section{Nurse quality variables}

Nurse perceived quality for pain (NQUALP) $\quad .08 \quad .05$

$\begin{array}{lllllll}\text { Nurse goal achievement for pain (NGOALP) } & .21 * * & .20 * & .31 * * * * & .18 * & .23 * * * & -.16\end{array}$

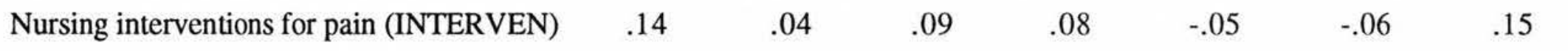

Note: $\mathrm{p}$ values are two tailed: ${ }^{*} \mathrm{p}<.1 ; * * \mathrm{p}<.05 ; * * * \mathrm{p}<.01 ; * * * * \mathrm{p}<.001 ; * * * * * \mathrm{p}<.0001$. 
Question 3: Is there a relationship between the patient-perceived quality (PQUALG and PQUALT) and patient beneficence (PAINDIM)?

No relationship was found between patient-perceived quality (PQUALG and PQUALT) and the pain diminished intensity score (PAINDIM) (see Table 5).

Question 4: Is there a relationship between patient-perceived quality (PQUALG and PQUALT) and nurse-perceived quality for pain (NQUALP) and between the patient-perceived quality (PQUALG and PQUALT) and the nurse-perceived quality score for interventions given for pain relief (INTERVEN)?

Spearman's correlation demonstrated no relationship between patient-perceived quality (PQUALG and PQUALT) and nurse-perceived quality for pain (NQUALP) (see Table 5). Also, no relationship was found between patient-perceived quality (PQUALG and PQUALT) and the nurse-perceived quality score for interventions given for pain relief (INTERVEN) (see Table 5).

Question 5: Is there a relationship between nurse goal achievement for pain (NGOALP) and the nurse-perceived quality score for interventions given for pain relief (INTERVEN)?

No relationship was shown between nurse goal achievement for pain (NGOALP) and nurse-perceived quality for interventions for pain relief (INTERVEN) (see Table 5). 


\section{CHAPTER V}

\section{DISCUSSION}

\section{Research Questions}

Question 1: Is there a relationship between patient-perceived quality (PQUALG and PQUALT) and patient value (PGOAL and PGOALP)?

Patient-perceived quality global (PQUALG) and Patient-perceived quality total (PQUALT). There was a significant positive correlation between patient-perceived quality global (PQUALG) and patient-perceived quality total (PQUALT) (see Table 5). This relationship was paramount to determining that patient-perceived quality global (PQUALG) and patient-perceived quality total (PQUALT) were measuring the same construct. This finding provides validity to the measurements. This findings is consistent with Larrabee's (1992) study.

Patient-perceived quality (PQUALG and PQUALT) and patient goal achievement (PGOAL and PGOALP). Patient-perceived quality (PQUALG and PQUALT) and patient goal achievement (PGOAL) were positively correlated (see Table 5). This finding was anticipated and supports the theoretical relationship between patient quality and patient value. Therefore, as goal achievement (pain relief) is met, the patient's perception of quality is increased. The relationship between patient-perceived quality (PQUALG and PQUALT) and patient value (PGOAL) was consistent with the findings in Larrabee's (1992) study. The relationship between patient-perceived quality (PQUALG and PQUALT) and patient value for pain (PGOALP) is consistent with findings in Hull's (1989) study.

A positive correlation between patient-perceived quality (PQUALG and PQUALT) and patient goal achievement (PGOAL and PGOALP) supports the supposition that the greater the value, the greater the perception of quality (Larrabee, 1992). Also, this finding 
demonstrates support for operationalizing value in Larrabee's (1992) Model of Quality as pain relief, because pain relief is a goal that is valued by the patient (Hull, 1989).

The relationship between patient-perceived quality (PQUALG and PQUALT) and patient goal achievement suggest that as nurses are better able to meet the patients goals, patients' perception of the quality nursing care will be heightened. As patient's perception of nursing care is increased the patients' perception of the quality of their overall care will be increased (Abramowitz, Cote \& Berry, 1987; Fleming, 1981; Steiber, 1989; Walker \& Restuccia, 1984). Thus, nursing executives have economic and humanitarian incentives to increase patient goal achievement. First, the economic incentive is related to the relationship between perception of quality of overall care and intent to return, intent to recommend (Doering, 1983; Meterko, Nelson, \& Rubin, 1990; Stamps \& Lapriore, 1987), and intent to sue (Marker, 1989). Economic incentive to increase patient goal achievement is also related to decreasing pain which studies have shown to decrease post-operative complications (Sydow, 1989) and speeding patient recovery (Jackson, 1989; Wasylak, Abbott, English, \& Jeans, 1990). Second, the humanitarian incentive for increasing patient goal achievement is the ability to assist patient's to meet their goals and experience decreased pain.

Increased patient goal achievement could be realized by nurses involving patients in the determination of their goals for hospitalization (Larrabee, 1992) and mutual goal setting (King, 1981; Parse, 1987). Specifically, patient goal achievement could be increased through the development of a pain management plan in conjunction with the patient and family. Assisting patients to develop realistic achievable goals and then assisting them to meet these goals could increase patients' perception of quality. Thus, nurse executives should teach nurses to help patients identify their own goals and to mutually set goals and goal achievement plans, assess the staff's level of compliance with this activity, and 
continue to research the implications of this type of goal setting, especially for patients with a chief compliant of pain.

\section{Question 2: Is there a relationship between patient value (PGOAL and PGOALP) and patient beneficence (PAINDIM)?}

Patient Goal Achievement (PGOAL) to Patient Goal Achievement for Pain $(P G O A L P)$. There was a significant positive relationship between patient goal achievement (PGOAL) and patient goal achievement for pain (PGOALP) (see Table 5). At the initial interview the patient was asked the three top goals for their hospitalization. The average of these three goals determined the PGOAL score and only the goal for pain relief was used for PGOALP. Therefore, this relationship was anticipated. The positive correlation between patient goal achievement (PGOAL) and patient goal achievement for pain is significant because it suggests that as patients achieve their goals of pain relief that they also achieve their overall goals for hospitalization. Therefore, if nurses set achievable goals, related to pain management, with the patient's participation, then his overall goals for hospitalization may also be achieved. This potential relationship could be investigated by determining if patient goal achievement for pain (PGOALP) is also positively correlated with the other two goals the patient listed for his hospitalization.

One factor that could have influenced the relationship between patient goal achievement and patient goal achievement and patient goal achievement for pain is that the patient's goals for hospitalization were often supported by or fused together with pain relief in this study. For example, the patient with deep vein thrombosis might set a goal of dissolving the thrombus, decreasing the swelling of the extremity, and decreasing pain. The goal of decreased pain may be met because the thrombus is dissolving and the swelling is decreasing, while the pain management itself could have been effective or ineffective.

The implications for nursing executives are related to three areas: practice, research, and education. Practice implications are related to pain management and goal 
setting. Nursing executives will need to establish practice guidelines for pain through interdisciplinary efforts. Pain management must then be monitored, through quality assessment and improvement processes, to maintain the guidelines at the current standards of care. Research is needed to determine the adequacy of the treatment plan in conjunction with the patient's overall goals. Finally, nurses require education regarding these guidelines and current research findings.

Patient value (PGOAL) to patient beneficence (PAINDIM). Patient goal achievement (PGOAL) was positively correlated with the pain diminished intensity score (PAINDIM) (see Table 5). This correlation supports the premise in Larrabee's (1992) Model of Quality that as well-being (beneficence) increases, patients place higher value on the achievement of these goals. Larrabee (1992) also found initial support for this relationship.

Again, the relationship between patient value (PGOAL) and patient beneficence (PAINDIM) may be influenced by the patient's goals for hospitalization being intertwined with the other goals. The patient may achieve diminished pain (beneficence) through medical or nursing interventions other than those provided for achievement of the pain relief goal.

This correlation suggests that when pain is diminished during the patient's hospitalization achievement of the patient's goals in general will be enhanced. Therefore, if health care providers can work together to effectively manage the patient's pain, the achievement of all patients' goals may be enhanced. As mentioned previously, the nursing executive must evaluate how well patients meet their goals, mutual goal setting, and the adequacy of the pain management through the quality assessment and improvement process. Not only should nursing executives evaluate practice, but also continue research and educate nurses about the relationship between the patients' achievement of all of his goals and pain relief as a goal. 
Patient value (PGOALP) to Pain diminished intensity score (PAINDIM). Despite the positive correlation between patient goal achievement and diminished pain, there was no correlation between patient goal achievement for pain (PGOALP) and the pain diminished intensity score (PAINDIM). This finding was not anticipated. Theoretically, there should have been a positive correlation between patient goal achievement for pain (PGOALP) and pain diminished intensity score (PAINDIM), because the well being (beneficence) of diminished pain should have lead to a higher value of this achievement of the goal of pain relief. Patient value for pain (PGOALP) and patient beneficence (PAINDIM) were measuring similar pain concepts. Patient value for pain (PGOALP) measured the patients' judgment of achieving pain relief (a goal valued by the patient) by the time of the exit interview. Patient beneficence (PAINDIM) measured diminished intensity of pain between the time of the initial interview and the time of the exit interview. Because both potentially promote well being, there should have been some correlation between patient value for pain (PGOALP) and patient beneficence (PAINDIM). Since there was no correlation, clearly these variables were not measuring the same construct. There are four plausible explanations for why there was no correlation between patient value for pain (PGOALP) and patient beneficence (PAINDIM).

The first explanation is related to the patient's goals. Perhaps the patients were not involved in the development of the pain management plan. Donovan, Dillon, and McGuire (1987) found that nurses do not involve patients in the pain management plan. If the plan was not developed mutually the patient and nurse may have had different expectations about the pain goal. Additionally, the patients could have listed pain relief as their first, second, or third goal for hospitalization. There may have been a difference in the relationship between patient value for pain (PGOALP) and patient beneficence (PAINDIM) based on the rank importance of the pain goal.

A second explanation may have been the patients' inaccurate memory of pain. 
Several studies have found that many patients did not accurately remember the amount of pain over periods of time and tended to underestimate pain intensity on recall (Jamison, Sbrocco, \& Parris, 1989; Jones, 1957; Linton \& Gotestam, 1983; Linton \& Melin, 1982; Merskey, 1975; Norvell, Gaston-Johansson \& Fridh, 1987; Rofe' \& Algom, 1985). Therefore, the patients may not have accurately remembered how bad the pain was on admission and thus did not accurately determine the degree to which they had achieved the goal of pain relief during the exit interview.

Third, pain diminished intensity score (PAINDIM) was calculated by subtracting the VAS symptom severity score at the initial interview from the VAS score for pain at the exit interview. The patients were asked their chief symptom for hospitalization and the severity of these symptoms. Only patients who reported pain in response to this question were included in this sample of 91 participants. Most of the patients mentioned other symptoms in addition to pain. At the exit interview the patient was asked specifically, "How much pain are you in right now?". Since the initial interview did not specifically ask about pain only, perhaps this question may not be the most sensitive measure for pain severity at that time. Perhaps a similar question to the pain question used in the exit interview may have measured diminished pain over time more accurately.

Finally, the magnitude of decrease in pain may have been an issue. All patients with any decrease in pain were included in this analysis. Perhaps, for some patients, the pain was not decreased to a tolerable level or the level that the patient defined as acceptable. A decrease in pain may not have been the patients' goal for pain, but the goal may have been pain relief or at least relief to a comfortable level. Therefore, if pain relief was the patient's goal, then this goal would not be met simply by a decrease in pain and there would not be a correlation between patient value for pain (PGOALP) and patient beneficence (PAINDIM).

Nursing executives must encourage research to measure patient goal achievement 
for pain (PGOALP) and the relationship between patient goal achievement for pain (PGOALP) and the pain diminished intensity score (PAINDIM) should be investigated. Understanding this relationship between diminished pain and goal achievement for pain would provide useful information to care providers who strive for effective pain management. Furthermore, nurses must assess nursing practice to determine how well they are meeting patients goals related to pain relief or diminished pain and educate nurses regarding patient goal setting and diminished pain.

\section{Question 3: Is there a relationship between the patient-perceived quality (PQUALG and PQUALT) and patient beneficence (PAINDIM)?}

There was no relationship between patient-perceived quality (PQUALG and PQUALT) and the pain diminished intensity score (PAINDIM) (see Table 5). This finding was not anticipated. In Larrabee's (1992) study, pain intensity at the time of exit interview was a predictor of patient-perceived quality (PQUALG and PQUALT). Theoretically, there should have been a positive relationship between the patient's pain relief (beneficence) and patient-perceived quality (Larrabee's, 1992). As pain relief increased (beneficence), patient perception of quality should have been increased. The lack of a relationship between patient-perceived quality (PQUALG and PQUALT) and the pain diminished intensity score (PAINDIM) is especially noteworthy because there was a relationship between patientperceived quality (PQUALG and PQUALT) and patient value for pain (PGOALP).

The most plausible explanation for the lack of a correlation between patientperceived quality (PQUALG and PQUALT) and patient beneficence (PAINDIM) was related to the measurement of the pain diminished intensity score (PAINDIM). As discussed earlier, perhaps PAINDIM was not an accurate measurement of diminished pain because the initial interview question was not specifically related to pain. This explanation is also supported by the fact that the amount of pain at the exit interview was negatively correlated $(\mathrm{r}=-0.26, \mathrm{p}=0.04)$ with patient-perceived quality total (PQUALT) and was a 
predictor of patient-perceived quality (PQUALG and PQUALT) in Larrabee's (1992) study. This explanation is also supported by the fact that there was a positive relationship between the pain diminished intensity score (PAINDIM) and patient goal achievement (PGOAL) and between patient goal achievement (PGOAL) and patient-perceived quality (PQUALG and PQUALT) (see Table 5).

It is imperative that nurse executives explore the relationship between patient perceived quality and diminished pain. Determination of the relationship between these variables could assist in improving management of a patient's pain and increasing the patient's perception of quality nursing care. This research must be accompanied by monitoring of and education of nurses regarding effective pain management and its relationship with patient-perceived quality.

\section{Question 4: Is there a relationship between patient-perceived quality} (PQUALG and PQUALT) and nurse-perceived quality for pain (NQUALP) and between the patient-perceived quality (PQUALG and PQUALT) and the nurse-perceived quality score for interventions given for pain relief (INTERVEN)?

Patient-perceived quality (PQUALG and PQUALT) and nurse-perceived quality for pain (NQUALP). Patient-perceived quality (PQUALG and PQUALT) was not correlated with nurse-perceived quality for pain (NQUALP) (see Table 5). This finding is unexpected because, theoretically the nurses' perception should be positively correlated with the patient's perception. However, the finding is consistent with the findings of the original study (Larrabee, 1992). The lack of correlation between these variables suggests four possible explanations.

First, one possible explanation in the lack of correlation between these variables was incomplete documentation, an explanation also offered in the original study (Larrabee, 1992). The program on the bedside terminal system used at the research site made 
documentation of nurse goal achievement simpler and quicker than documentation of many of the interventions. The nurse may not have documented all of the nursing care given for the treatment or prevention of pain. This notion is supported by the findings that the mean score for nurse-perceived quality for pain (NQUALP) was much lower that the mean score for nurse goal achievement (NGOALP). In other words, the nurses may have given care which they did not document. The nurse quality data used in the study were limited to that data documented in the chart.

Second, the lack of correlation between the patient-perceived quality (PQUALG and PQUALT) and nurse-perceived quality for pain (NQUALP) may be related to the tendency of patients to overrate nursing care and hospital care (Hays, Nelson, Rubin, Ware, \& Meterko, 1991). This idea is supported by the mean scores of patient-perceived quality (PQUALG and PQUALT) in this study. The mean scores for patient-perceived quality (PQUALG and PQUALT) were much higher than the mean score for nursing perceived quality for pain (NQUALP) (see Table 4). This explanation was also discussed in the original study (Larrabee, 1992). Alternately, negatively skewed scores for patientperceived quality (PQUALG and PQUALT) may be a measurement problem. The right hand anchor was changed from "excellent" to "very good" to limit the reading difficulty to the sixth grade. Because "very good" is not superlative, this anchor may have produced a "ceiling effect" (Larrabee, 1992).

Third, this lack of correlation suggests that perhaps patients cannot evaluate some aspects of their care which the nurse can evaluate as suggested by Larrabee (1992). The differences between the patients' evaluation of quality nursing care and the nurses evaluation of nursing care is important because this may be the beginning point of bringing the patients' perception and nurses' perception to an agreement point.

Finally, the lack of correlation between the patient's perceived quality and the nurse's perceived quality suggests that nurses and patients do not always agree on the 
definition of quality nursing care (Bader, 1988; Brown, 1992; Doering, 1983; Erikson, 1987; Fleming, 1981; Marker, 1989; Merry, 1987; Meterko, Nelson, \& Rubin, 1990; Omachonu, 1990; Rempusheski, Chamberlain, Picard, Ruzanski, \& Collier, 1988; Rubin, 1990; Spitzer, 1988; Stamps \& Lapriore, 1987; Steiber, 1989), especially quality of care related to pain management (Bond \& Pilowsky, 1966; Carr, 1990; Choiniere, Melzack, Girand, Rhondeau, \& Paquin, 1990; Cohen, 1980; Donovan, Dillon, \& McGuire, 1987; Dudley \& Holm; 1984; Favaloro \& Touzel, 1990; Fox, 1982; Marks \& Sachar, 1984; McCaffery \& Ferrell, 1991; Melzack, 1990; Puntillo, 1990; Rankin \& Snider, 1984; Winefield, Katsikitis, Hart, \& Rounsefell, 1990). Larrabee (1992) noted that perception of quality may be dependent on role. Nurses have typically defined quality as conformance to standards of care (Bader, 1988; Brown, 1992; Doering, 1983; Donabedian, 1991; Erikson, 1987; Fleming, 1981; Marker, 1989; Merry, 1987; Meterko, Nelson, \& Rubin, 1990; Omachonu, 1990; Rubin, 1990; Stamps \& Lapriore, 1987), while patients have typically defined quality related to hotel-like amenities (Abramowitz, Cote \& Berry, 1987; Doering, 1983; Fleming, 1981; Stamps \& Lapriore, 1987; Walker \& Restuccia, 1984). However, patient perception of quality has been correlated with care-comfort activities (Hinshaw \& Atwood, 1982) and pain at the exit interview (Larrabee, 1992).

If these interpretations are correct, nursing executives need to assure nursing quality assessment and improvement activities and the education of nurses regarding the documentation of nursing care. These executives must facilitate research to measure the patients' perception of quality of nursing care. Nurses must be educated regarding how to increase patient-perceived quality and the importance of improving this perception. There are some technical aspects of nursing care which are difficult for patients to evaluate. Nurses must continue to evaluate the technical aspects of nursing care through their quality assessment and improvement activities and yet evaluate patient education regarding these services. Increased patient understanding of technical aspects of care must be a focus of 
nursing education and research activities by attempting to help the patient to evaluate these services through patient education. In this study, the nurse might discuss the following with Mr. Jones, "after your surgery you should expect the nurse to...". Finally, nursing executives should continue to facilitate research related to patients' definition of quality nursing care. Nurses should evaluate on admission what the patient considers to be quality patient care, while sharing with the patient the nurses' perception of what the patient can expect as quality care. This improved communication might assist nurses and patients to find a mutual definition of quality. Possibly a mutual definition of quality nursing care would assist nurses to meet consumer expectations better.

Patient-perceived quality (PQUALG and PQUALT) to nurse-perceived quality score for interventions for pain relief (INTERVEN). There was no relationship between patient-perceived quality (PQUALG and PQUALT) and nurse-perceived quality score for interventions given for pain relief (INTERVEN) (see Table 5), even though the mean scores were not different (see Table 4). This finding was unexpected. Theoretically, one would expect a relationship between how well the nurse intervened for the patient's pain and the patient's perception of quality. Several possible factors may have influenced this lack of a relationship.

The first explanation for the lack of correlation between patient-perceived quality (PQUALG and PQUALT) and nurse-perceived quality for interventions for pain relief (INTERVEN) is the documentation of the nursing intervention. Perhaps there were some interventions performed which were not documented in the record. Also, the nurses may have only documented the intervention when the intervention was pain medication administration. For example, $97 \%$ of the interventions documented were medication given for pain relief.

Second, perhaps nurses primarily intervene for pain using only medication. This idea is supported by several studies which have found that nurses primarily only give 
medication to treat pain (Carr, 1990; Donovan, Dillon, \& McGuire, 1987; Winefield, Katsikitis, Hart, \& Rounsefell, 1990).

Third, compliance with standards for interventions is another potential explanation for the lack of relationship between patient-perceived quality (PQUALG and PQUALT) and nurse-perceived quality for interventions for pain relief (INTERVEN). The variable INTERVEN was determined as the percentage of times the nurse responded within 30 minutes when the patient complained of pain. The standard of nursing care at the research site requires that nursing process indicators be met at least $90 \%$ of the time in order to represent quality patient care. Therefore, the nurse must respond within 30 minutes to the patient's compliant of pain at least $90 \%$ of the time for the care to be considered quality. In this study, $49 \%$ of the participants had an intervention score less than $90 \%$. Perhaps there is a difference in the hypothesized relationship of patient-perceived quality (PQUALG and PQUALT) to nurse-perceived quality for interventions for pain relief (INTERVEN) between the groups of patients above the $90 \%$ threshold and the group of patients below the $90 \%$ threshold. Those above the $90 \%$ threshold may have shown a relationship between patient-perceived quality (PQUALG and PQUALT) and nurse-perceived quality score for interventions given for pain relief (INTERVEN).

Fourth, differences in management of pain in particular disease entities could be an explanation for a lack of relationship between patient-perceived quality (PQUALG and PQUALT) and nurse-perceived quality score for interventions given for pain relief (INTERVEN). For patients with disease states which nurses have had little education regarding the management of pain the intervention score was below the $90 \%$ threshold. For example, $86 \%$ of the Sickle Cell patients in the study $(n=7)$ had intervention scores of less than 90\%. Other examples were patients with Pelvic Inflammatory Disease $(n=6)$, cellulitis ( $n=6)$, and Crohn's Disease $(n=2)$, who had intervention scores of less than $90 \%$ in $83 \%, 83 \%$, and $100 \%$ of these patients respectively. However, interventions for pain 
occurred more frequently in disease states in which there is a larger current state of knowledge of pain management. For example, four of the five patients (80\%) with cancer had intervention scores above $90 \%$. Another explanation might be that some of these disease states require more frequent interventions for pain and the nurses were unable to attend to these patients pain in a timely manner.

Therefore, the nursing executives must continue to monitor their practice and research how nurses intervene for patients with pain and ensure the documentation of these interventions. Also, practice assessments and research must monitor and determine the types of intervention. Nurses must be educated in universal pain management techniques and those which are appropriate to specific disease states. This education should include interventions other than medication. Last, nursing executives must continue to assess practice, research, and educated nursing regarding the relationship between these variables.

Question 5: Is there a relationship between nurse goal achievement for pain (NGOALP) and the nurse-perceived quality score for interventions given for pain relief (INTERVEN)?

The nurse goal achievement for pain (NGOALP) was not correlated to the nurseperceived quality score for interventions given for pain relief (INTERVEN) (see Table 5). This was a surprising finding. Theoretically, if the nurses goal is related to pain relief there should be a relationship between nurse goal achievement for pain (NGOALP) and the nurse-perceived quality for interventions for pain relief (INTERVEN). The lack of correlation between these variables suggests several possible factors.

The first possible factor, in the lack of correlation between nurse goal achievement for pain (NGOALP) and the nurse-perceived quality score for interventions given for pain relief (INTERVEN), is the nurse's choice of the goal or goals. There were two goals the nurses used in the plan of care: 1) "Patient/Family will participate in pain management plan developed [with] staff" (goal 1) and 2) "Patient will verbalize a decrease in or relief of 
identified pain" (goal 2). The nurse chose one or both of these goals. There was no documentation on any of the charts of the patient participating in the pain management plan for goal 1. Therefore, when goal 1 was chosen the data were missing. For several $(n=5)$ subjects, goal 1 was the only goal chosen. Therefore, either there was no pain management plan discussed with the patient or there was not documentation of this plan. Donovan, Dillon, \& McGuire (1987) also found that the patient was not included in the pain management plan.

A second possible factor contributing to the lack of a relationship between nurse goal achievement for pain (NGOALP) and nurse-perceived quality for interventions for pain relief (INTERVEN) is that the pain goals on the nursing plan of care are insufficient to adequately determine the effectiveness of pain management. Alternative goals might capture effectiveness of pain management better. For example, "The patient will have a decrease in identified pain to a level of 0 (on a scale of $0-10,0=$ no pain, $10=$ highest pain possible) or to a patient determined comfort level." This goal is much more measurable. In the original goal 2, if the patient had any decrease in pain, then the goal was met, for instance, a decrease of 10 to 9 . However, a score of 9 is not an acceptable level of pain relief.

Thirdly, the assessment of pain relief or the documentation of the patients' relief of pain was a possible factor in the lack of correlation between patient goal achievement for pain (PGOALP) and nurse-perceived quality for interventions for pain relief (INTERVEN). The nurses in this study did not always assess the patients following the nursing interventions for pain or did not document this assessment. The lack of an assessment or the lack of documentation of an assessment has been a problem in other studies (Bond \& Pilowsky, 1966; Carr, 1990; Donovan, Dillon, \& McGuire, 1987; Fox, 1982; Puntillo, 1990).

Nurse executives should monitor how nurses assess pain and the documentation of 
this assessment through their nursing quality assessment and improvement activities. Also, nursing executives should establish pain management practice guidelines with measurable goals or outcomes for the patients. Only through the improvement of the way nurses assess pain and establish appropriate goals will the patient begin to receive adequate treatment of their pain. They should continue to encourage research which identifies ways to improve documentation and educate nurses regarding how to document pertinent patient information.

\section{Strengths and Limitations}

\section{Generalizability}

This study can be generalized to other safety net hospitals with similar make up of predominantly black, young patients. However, generalizability is limited to Medical/Surgical adult patients on units with computerized documentation (Larrabee, 1992).

\section{Validity}

As in Larrabee's (1992) study, there have been no standardized instruments developed to measure patient goal achievement, nurse goal achievement, or nurse-perceived quality as the variables are defined in this study. However, inter-rater reliability was established in the original study (Larrabee, 1992). The instrument for measuring nurse goal achievement and nurse quality had content validity because it used the nursing process as the standards source for evaluating quality. Assumptions were made that the questions used for the new data (INTERVEN) would measure nurse-perceived quality for intervention for pain relief (INTERVEN). Also, the response format, the VAS, has been validated for use with subjective phenomena (Davies, Burrows, \& Poynton, 1975; Gift, 1989; Gift, Plaut, \& Jacox, 1986; Little \& McPhail, 1973; Wewers \& Lowe, 1990) including pain assessment (Beyer \& Levin, 1987; Houde, 1982; Jacox, 1977; McCaffery 
\& Beebe, 1989; McGuire, 1984; US. Department of Health and Human Services, 1992; Wallenstein, 1984).

\section{Measurement in Future Research}

There are at least three measurement issues which future researchers should consider. First, to more accurately measure change in pain over time, future studies should use a different tool to assess pain at initial contact. Second, to more accurately measure nurse goal achievement for pain relief, one should use a more sensitive measure than nurse goal achievement for pain (NGOALP) as defined in this study. The McGill Short form questionnaire, which has been effectively used in other studies, would be a reasonable alternate for measuring both change in pain over time, patient goal achievement for pain, and nurse goal achievement for pain (Houde, 1982; Melzack, 1987; Savedra, Gibbons, Tesler, Ward, \& Wegner, 1982; Wilkie, Holzemer, Tesler, Ward, Paul, \& Savedra, 1990; Wilkie, Savedra, Holzemer, Tesler, \& Paul, 1990). Third, as mentioned in Larrabee's (1992) study, either an alternate response format or a more superlative right-hand anchor should be used to measure patient-perceived quality (PQUALG and PQUALT). This would help clarify whether a ceiling effect existed in these data due to instrument design or due to a tendency of patient to report high perceptions of quality.

\section{Future Research Questions}

The findings of this study suggest several additional questions about the relationships between the variables. The following are questions which should be addressed in future research:

1. Is there a relationship between the patient-perceived quality for pain and the patientperceived quality of nursing care?

2. Is there a relationship between the patient's perception of the effectiveness of the pain management plan and the patient-perceived quality of nursing care? 
3. Are there differences in the patient's perception of the effectiveness of the pain management plan and the patient's perceived quality between patients with different medical diagnosis?

4. Is there a relationship between the patient's participation in goal setting and pain management plan and the patient's perception of quality?

5. Is there a relationship between the patients achievement of other goals for hospitalization and the patients goal achievement for pain?

6. Is there a relationship between the patient's involvement in the pain management plan and patient goal achievement?

7. Is there a difference in patient-perceived quality scores between patients with INTERVEN scores greater than or equal to $90 \%$ and patients with INTERVEN score less than $90 \%$ ?

8. Are there differences between the nurse-perceived quality, nurse goal achievement scores, patient-perceived quality, and patient goal achievement before implementation of pain management guidelines and after implementation of pain management guidelines?

\section{Conclusion}

As competition and cost of care continue to increase in health care, providers, in general, and nurses in particular must begin to examine ways of decreasing costs while maintaining or increasing quality, market share, and patient satisfaction. This study examined the relationship between patient quality and patient value, nurse quality, and nurse value for patients who reported pain at the time of the initial interview. There were three key findings.

A positive relationship was demonstrated between patient-perceived quality (patient quality) and patient goal achievement (patient value). As patient goal achievement increased, so did patient-perceived quality. Specifically, this relationship was 
demonstrated between both measures of patient-perceived quality (patient quality) and patient goal achievement for pain (patient value). Also, a positive relationship was demonstrated between both measures of patient value (patient goal achievement and patient goal achievement for pain). This suggests that patient goal achievement for pain may enable achievement of other goals. The implications for nursing executives are 1) to further explore the relationship between patient goal achievement for pain and achievement of other goals and 2) to pursue avenues to increase mutual goal setting in order to increase patientperceived quality.

Second, this study failed to demonstrate a relationship between patient-perceived quality (patient quality) and diminished pain (patient beneficence). However, a positive relationship was demonstrated between patient goal achievement (patient value) and diminished pain (patient beneficence) such that the patient goal achievement scores were higher when the amount of decrease in pain was higher. The implications for nursing executives is to pursue avenues to effectively manage patients' pain because diminished pain is associated with higher patient goal achievement, which, in turn, is associated with higher patient-perceived quality.

Third, this study failed to demonstrate a relationship between patient-perceived quality and nurse-perceived quality. Theoretically, as nurse-perceived quality increase, patient-perceived quality should increase. Nursing executives further investigate the alternative explanations for why this theoretical relationship was not demonstrated. Such investigations should provide nursing executives with additional information that could guide quality improvement efforts.

In conclusion, nursing executives have humanitarian and economic incentives to improve pain management, mutual goal setting, development of pain management plan with patient and interdisciplinary collaboration, evaluation of pain management effectiveness, and to further investigate the relationships among patient quality, patient value, nurse 
quality, and nurse value, and pain. The humanitarian incentive is a pain free patient receiving quality care. Because patient satisfaction is directly related to patients intent to return, intent to recommend, and intent to sue, the economic incentive is market share maintenance, a strong incentive in today's highly competitive market. 
REFERENCES 


\section{LIST OF REFERENCES}

Abramowitz, S., Cote, A. A., \& Berry, E. (1987). Analyzing patient satisfaction: A multianalytic approach. Quality Review Bulletin, 13, 122-130.

American Pain Society. (1989). Principles of analgesic use in the treatment of acute pain and chronic cancer pain (2nd ed.). Skokie: American Pain Society.

Anderson, K. \& Poole, C. (1983, Aug). Self-administered medication on a postpartum unit. American Journal of Nursing, 1178-1180.

Bader, M. M. M. (1988). Nursing Care Behaviors that predict patient satisfaction. Journal of Nursing Quality Assurance, 2(3), 11-17.

Baggerly, J. (1986). Epidural catheters for pain management: The nurse's role. Journal of Neuroscience Nursing, 18, 290-295.

Barswick, A. \& Llewellyn, J. (1982). A comparison of the anxiety-reducing potential of two techniques of bathing. Nursing Research, 31, 22-24.

Beaver, W. T. (1980). Management of cancer pain with parental medication. Journal of the American Medical Association, 244(3), 2653-2657.

Bell, M. D., Mishra, P., Weldon, B. D., Murray, G. R., Calvey, T. N., \& Williams, N. E. (1985). Buccal morphine - A new route for analgesia? The Lancet, 1, 71-73.

Beyer, J. E. \& Levin, C. R. (1987). Issues and advances in pain control in children. Nursing Clinics of North America, 22(3), 661-675.

Bond, M. R. \& Pilowsky, I. (1966). Subjective assessment of pain and its relationship to the administration of analgesics in patients with advanced cancer. Journal of Psychosomatic Research, 10, 203-208.

Bonica, J. J. (1990). History of pain concepts and therapies. In The Management of Pain (2nd ed.). Philadelphia: Lea \& Febiger.

Bragg, C. L. (1989). Practical aspects of epidural and intrathecal narcotic analgesia in the intensive care setting. Heart \& Lung, 18, 599-608.

Broome, M. E., Bates, T. A., Lillis, P. P., \& McGahee, T. W. (1990). Children's medical fears, coping behaviors, and pain perceptions during a lumbar puncture. Oncology Nursing Forum, 17, 361-366.

Brown, D. S. (1992). A conceptual framework of nursing service quality. Journal of Nursing Care Quality, 6(4), 66-74.

Caballero, G. A., Ausman, R. K., \& Himes, J. (1986). Epidural morphine sulfate by continuous infusion with an external pump for pain management in oncology patients. The American Surgeon, 52, 402-405.

Cahill, C., Panzarella, C., \& Spross, J. A. (1990). Pediatric cancer pain. Oncology Nursing Forum, 17, 948-951. 
Campbell, C. F., Mason, J. B., \& Weiler, J. M. (1990). Patient perception of hospitalization as an avenue to change. Journal of Quality Assurance, 5(1), 8-15.

Campbell, J. L., Grant, K. L., Royster, E., \& Thweatt, J. K. (1990). Journal of Nursing Quality Assurance, 5(1), 8-15.

Carr, E. C. J. (1990). Postoperative pain: Patients' expectations and experiences. Journal of Advanced Nursing, 15, 89-100.

Choiniere, M., Melzack, R., Girand, N., Rhondeau, J., \& Paquin, M. J. (1990). Comparisons between patients' and nurses' assessment of pain and medication efficacy in severe burn injuries. Pain, 40, 143-152.

Cohen, F. L. (1980). Postsurgical pain relief: Patients' status and nurses' medicine choices. Pain, 2, 265-274.

Consumer Reports. (1992, July). Health care dollars, 435-449.

Crowley, B. C., Lubesnick, K., \& Sylwestrak, M. L. (1991). Clinical indicators: A tool for improving pain management documentation. Journal of Nursing Care Quality, 6, 40-46.

Davies, B., Burrows, G., \& Poynton, C. (1975). A comparative study of four depression rating scales. Australian and New Zealand Journal of Psychiatry, 2(1), 21-24.

DiMotto, J. W. (1984, June). Relaxation. American Journal of Nursing, 754-758.

Doering, E. R. (1983). Factors influencing inpatient satisfaction with care. Quality Review Bulletin, 2, 291-299.

Donabedian, A. (1991, Oct). The roles of outcomes in quality assessment and assurance. Unpublished lecture conducted at the meeting of the Annual Conference of Nursing Quality Assurance.

Donabedian, A. (1988). The quality of care: How can it be assessed? Journal of the American Medical Association, 260(12), 1743-1748.

Donovan, M., Dillon, P., \& McGuire, L. (1987). Incidence and characteristics of pain in a sample of medical-surgical inpatients. Pain, $\underline{30,69-78 . ~}$

Dudley, S. R. \& Holm, K. (1984). Assessment of the pain experience in relation to selected nurse characteristics. Pain, 18, 179-186.

Eastaugh, S. (1992). Marketing, pricing, and specialization. In Health Care Financing: Economic Incentive and Productivity Enhancement. New York: Auburnhouse.

Eland, J. M. (1988). Pain management and comfort. Journal of Gerontological Nursing, $14,10-15$.

Erikson, L. R. (1987). Patient satisfaction: An indicator of nursing care quality. Nursing Management, 18, 31-35. 
Fakouri, C. \& Jones P. (1987). Relaxation rx: slow stroke back rub. Journal of Gerontological Nursing, 13, 32-35.

Favaloro, R. \& Touzel, B. (1990). A comparison of adolescents and nurses' postoperative pain rating and perceptions. Pediatric Nursing, 16, 414-424.

Feldstein, P. J. (1988). An introduction to the economics of medical care. In Health Care Economics (3rd ed.). Irvine: Delmar Publishers.

Ferrell, B. R., Wisdom, C. Rhiner, M., \& Alletto, J. (1991). Pain management as a quality of care outcome. Journal of Nursing Quality Assurance, $\underline{5}(2), 50-58$.

Fleming, G. V. (1981). Hospital structure and consumer satisfaction. Health Services Research, 16, 43-63.

Foley, K. M. \& Inturrisi, C. E. (1987). Analgesic drug therapy in cancer pain: principles and practice. Medical Clinics of North America, 71(2), 207-213.

Foley, K. M. (1985). The treatment of cancer pain. The New England Journal of Medicine, $\underline{313}(2), 84-93$.

Fox, L. S. (1982). Pain management in the terminally ill cancer patient: An investigation of nurses' attitudes, knowledge, and clinical practice. Military Medicine, 147, 455459.

Frack, L. S. (1986). A new method to quantitatively describe pain behavior in infants. Nursing Research, $35(1), 28-31$.

Gift, A. G. (1989). Visual analogue scales: Measurement of subjective phenomena. Nursing Research, 38(5), 286-288.

Gift, A. G., Plaut, S. M., \& Jacox, A. K. (1986). Psychologic and physiologic factors related to dyspnea in subjects with chronic obstructive pulmonary disease. Heart and Lung, 15, 595-601.

Geden, E., Beck, N., Hauge, G., \& Pohlman, S. (1984). Self-report and psychophysiological effects of five pain-coping strategies. Nursing Research, 33, 261-265.

Guralnik, D. B. (ed). (1982). Webster's New World Dictionary of the American Language (2nd College ed.). New York: Simon \& Schuster.

Hansberry, J. L., Bannick, K. H., \& Durkan, M. J. (1990, Oct). Managing chronic pain with a permanent epidural catheter. Nursing, 52-59.

Hays, R. D., Nelson, E. C., Rubin, H. R., Ware, J. E., \& Meterko, M. (1991). Further evaluations of the PJHQ scales. (Suppl.). Medical Care, 28(9), 29-39.

Hinshaw, A. S. \& Atwood, J. R. (1982). A patient satisfaction instrument: Precision by replication. Nursing Research, 31, 170-191. 
Hodes, R. L., Howland, E. W., Lightfoot, N. \& Cleeland, C. S. (1990). The effects of distraction on responses to cold pressor pain. Pain, $\underline{41}, 109-114$.

Holm, K., Cohen, F., Dudas, S., Medema, P. G., \& Allen, B. L. (1989). Effect of personal pain experiences on pain assessment. Image: Journal of Nursing Scholarship, 21, 72-75.

Houde, R. W. (1982). Methods for measuring clinical pain in humans. Acta Anaesthesia Scandinavia, (Suppl. 74), 25-29.

Howard-Ruben, J. \& McGuire, L. (1990). Nursing's role in pain management. In The Management of Pain (2nd ed.). Philadelphia: Lea \& Febiger.

Hull, M. (1989). Family needs and supportive nursing behaviors during terminal cancer: A review. Oncology Nursing Forum, 16(6), 787-792.

Jackson, D. (1989). A study of pain management: Patient controlled analgesia. Journal of Intravenous Nursing, $12,42-57$.

Jacox, A. K. (1977). Pain: A source book for nurses and other health professionals. Boston: Little Brown and Company.

Jamison, R. N., Sbrocco, T. \& Parris, W. C. V. (1989). The influence of physical and psychosocial factors on accuracy of memory for pain in chronic pain patients. Pain, 37, 289-294.

Joint Commission Accreditation of Healthcare Organizations. (1992). Strategies for quality improvement in nursing. (3rd ed.). Field Education Programs.

Jones, E. (1957). Pain. International Journal of Psychoanalysis, 38, 255-257.

Keefe, F. J. \& Williams, D. A. (1990). A comparison of coping strategies in chronic pain patients in different age groups. Journal of Gerontology, 45(4), 161-165.

Keller, E. \& Bzdek, V. (1986). Effects of therapeutic touch on tension headache pain. Nursing Research, 35, 101-105.

King, I. M. (1981). A theory for nursing: Systems, concepts, process. New York: John Wiley \& Sons.

King, K. B., Norsen, L. H., Robertson, R. K., \& Hicks, G. L. (1987). Patient management of pain medication after cardiac surgery. Nursing Research. 36(3), $145-150$.

Kwentus, J. A., Harkins, S. W., Lignon, N., \& Silverman, J. J. (1985). Current concepts of geriatric pain and its treatment. Geriatrics, 40(4), 48-54.

Lamontagne, L. L., Mason, K. R., \& Hepworth, J. T. (1985, Sept/Oct). Effects of relaxation on anxiety in children: Implications for coping with stress. Nursing Research, 34, 289-292. 
Larrabee, J. H. (1992). Hospital patients' and nurses' perceptions of quality. (Doctoral dissertation, University of Tennessee, Memphis, 1992). Dissertation Abstracts International, 53/08-B, 4030 .

Leib, R. A. \& Hurtig, J. B. (1985). Epidural and intrathecal narcotics for pain management. Heart \& Lung, 14, 164-173.

Linton, S. J. \& Gotestam, G. K. (1983). A clinical comparison of two pain scales: Correlation, remembering chronic pain and a measure of compliance. Pain, 17, 5765 .

Linton, S. J. \& Melin, L. (1982). The accuracy of remembering chronic pain. Pain, 13 , 281-285.

Little, J. C. \& McPhail, N. I. (1973). Measures of depressive mood at monthly intervals. British Journal of Psychiatry, 122, 447-452.

Loeser, J. D. \& Cousins, M. J. (1990). Contemporary pain management. The Medical Journal of Australia, 153(4), 208-216.

Magnani, B., Johnson, L. R., \& Ferrante, F. M. (1987). Modifiers of patient controlled analgesia efficiency: Chronic pain. Pain, $\underline{39}, 23-29$.

Marchette, L., Main, R., Redick, E., Bagg, A., \& Leatherland, J. (1991). Pain reduction interventions during neonatal circumcision. Nursing Research, 40(4), 241-244.

Marker, J. (1989. Dec/Jan). Integrating patient satisfaction into your QA/RM program Or pleased patients seldom sue. Journal of Quality Assurance, 8-10, 39.

Marks, R. M. \& Sachar, E. J. (1980). Undertreatment of medical inpatients with narcotic analgesics. Annuals of Internal Medicine, $301,123$.

McCaffery, M. \& Beebe, A. (1989). Pain: Clinical manual for nursing practice. St. Louis: C.V. Mosby Company.

McCaffery, M. \& Ferrell, B. (1991). How would you respond to these patients in pain? Nursing, 21, 34-37.

McCaffery, M. (1981, June). When your patient's still in pain, don't just do something: Sit there. Nursing, 59-61.

McGuire, D. M. (1984). The measurement of clinical pain. Nursing Research, 33(3)m 152-156.

McGuire, L. \& Wright, A. (1984, Dec). Continuous Narcotic infusion: It's not just for cancer patients. Nursing, 50-55.

Melzack, R. (1990). The tragedy of needless pain. Scientific American, 262(2), 27-33.

Melzack, R. (1987). The short-form McGill pain questionnaire. Pain, 30, 191-197. 
Melzack, R., Guite, S., \& Gonshor, A. (1980, Jan 6). Relief of dental pain by ice massage of the hand. Canadian Medical Association Journal, 122, 189-191.

Merry, M. D. (1987, Sept). What is quality care? A model for measuring health care excellence. Quality Review Bulletin, 298-301.

Merskey, H. (1975). Pain, learning, and memory. Journal of Psychosomatic Research, $19,319-324$.

Meterko, M., Nelson, E. C., \& Rubin, H. R. (1990). Patient judgment of hospital quality: report of a pilot study. Medical Care (Suppl.), 28(9), S1-S44.

Miller, K. M. (1987). Deep breathing relaxation. American Operating Room Nursing Journal, 45, 484-488.

Norvell, K. T., Gaston-Johansson, F. \& Fridh, G. (1987). Remembrance of labor pain: How valid are retrospective pain measurements? Pain, $\underline{31}$, 77-86.

Omachonu, V. K. (1990). Quality of care and the patient: New criteria for evaluation. Health Care Management Review, 15, 43-50.

Paice, J. A. (1987). New delivery systems in pain management. Nursing Clinics of North America, 22(3), 715-725.

Parse, R. R. (1987). Nursing Science: Major paradigms, theories, and critiques. Philadelphia: W. B. Saunders Company.

Pirsig, R. M. (1974). Zen and the art of motorcycle maintenance. New York: William Morrow \& Co.

Portenoy, R. K., Foley, K. M., \& Inturrisi, C. E. (1990). The nature of opioid responsiveness and its implications for neuropathic pain: New hypotheses derived from studies of opioid infusions. Pain, 43(3), 273-286.

Prehn, R. A., Mayo, H., \& Weisman, E. (1989). Determining the validity of patient perceptions of quality care. Quality Review Bulletin, 15(3), 74-79.

Puntillo, K. A. (1990). Pain experiences of intensive care unit patients. Heart \& Lung, $19,526-534$.

Rankin, M. A. \& Snider B. (1984). Nurses perception of cancer patients' pain. Cancer Nursing, 7(2), 149-154.

Reichheld, F. F. \& Sasser, W. E. (1990, Sept-Oct). Zero defects: Quality comes to services. Harvard Business Review, 105-111.

Rempusheski, V. F., Chamberlain, S. L., Picard, H. B., Ruzanski, J., \& Collier, M. (1988). Expected and received care: Patients perceptions. Nursing Administration Quarterly, 12(3), 42-50.

Roef', Y. \& Algom, D. (1985). Accuracy of remembering postdelivery pain. Perception Motor Skills, 60, 99-105. 
Rosner, B. (1990). Fundamentals of biostatistics. (3rd ed.). Boston: PWS-Kent.

Rubin, H. R. (1990). Can patients evaluate the quality of hospital care? Medical Care Review, 47(3), 267-326.

Sanford, K. D. \& Schlicher, C. M. (1986, Sept/Oct). Pain management: Are your biases showing? NursingLife, 47-51.

SAS Institute Inc. (1989). SAS ${ }^{\mathrm{r}}$ user's guide: Statistics, version 6, fourth edition, Volume 2. Cary, NC: Author.

SAS Institute Inc. (1990). SASr user's guide: Statistics, version 6, fourth edition. Volume 1. Cary, NC: Author.

Savedra, M., Gibbons, P., Tesler, M., Ward, J., \& Wegner, C. (1982). How do children describe pain? A tentative assessment. Pain, 14, 95-104.

Smith, M. S. \& Womack, W. M. (1987). Stress management techniques in childhood and adolescence. Clinical Pediatrics, 26(11), 581-585.

Spiegel, D. (1985). The use of hypnosis in controlling cancer pain. CA-A Cancer Journal for Clinicians, 35 (4), 221-230.

Spitzer, R. B. (1988). Meeting consumer expectations. Nursing Administration Quarterly, 12(3), 31-39.

Stamps, P. L. \& Lapriore, E. H. (1987). Measuring patient satisfaction in a community hospital. Hospital Topics, 65 , 22-26.

Steiber, S. R. (1989, April 5). Social issues: How consumers perceive health care quality. Hospitals, 84 .

Steward, S. M. (1986). Controlling pain with epidural narcotics: Nursing implications. Critical Care Nurse, 6 , 50-56.

Swafford, L. I. \& Allan, D. (1968). Pain relief in the Pediatric Patient. Medical Clinics of North America, 52(1), 131-135.

Sydow, F. W. (1989). The influence of anesthesia and postoperative management on lung function. Acta Chiurgical Scandinavian, 550(Suppl.), 159-165.

Taylor, A. G. \& Haussmann, G. M. (1988). Meaning and measurement of quality nursing care. Applied Nursing Research, 1(2), 84-88.

Taylor, A. G., Hudson, K., \& Keeling, A. (1991). Quality nursing care: The customers' perspective revisited. Journal of Nursing Quality Assurance, 5, 23-31.

U. S. Department of Health and Human Services, Public, Health Service, Agency for Health Care Policy and Research. (1992). Acute pain management: Operative or medical procedures and trauma. (AHCPR Pub. No. 92-0032). Rockville, MD. 
Villarruel, A. M. \& de Montellano, B. D. (1992). Culture and pain: A mesoamerican perspective. Advanced Nursing Science, 15(1), 21-32.

Walker, A. H. \& Restuccia, J. D. (1984). Obtaining information on patient satisfaction with hospital care: Mail versus telephone. Health Services Research, 19, 291-306.

Walker, J. B. \& Katz, R. L. (1981). Non-opioid pathways suppress pain in humans. Pain, 11, 347-354.

Wallenstein, S. L. (1984, May 15). Measurement of pain and analgesia in cancer patients. (Suppl.). Cancer, 53, 2260-2264.

Wasylak, T. J., Abbott, F. V., English, M. J. \& Jeans, M. E. (1990). Reduction of postoperative morbidity following patient-controlled morphine. Canadian Journal of Anaesthesia, 37, 726-731.

Weisbrod, B. A. (1985, Sept-Oct). America's health care dilemma. Challenge, 30-34.

Wells, N. (1982). The effect of relaxation on postoperative muscle tension and pain. Nursing Research, 31, 236-238.

Wewers, W. E. \& Lowe, N. K. (1990). A critical review of visual analogue scales in he measurement of clinical phenomena. Research in Nursing and Health, 13(4), 227236.

White, P. F. (1988). Use of patient-controlled analgesia for management of acute pain. Journal of the American Medical Association, 259, 243-247.

Whitman, H. H. (1984, July). Sublingual morphine: A novel route of narcotic administration. American Journal of Nursing, 939.

Wild, L. (1990). Pain management. Critical Care Nursing Clinics of North America, 2(4), 537-547.

Wilkie, D. J. (1990). Cancer pain management: State-of-the-art nursing care. Nursing Clinics of North America, 25(2), 331-343.

Wilkie, D. J., Holzemer, W. L., Tesler, M. D., Ward, J. A., Paul, S. M., \& Savedra, M. C. (1990). Measuring pain quality: Validity, and reliability of children's and adolescents' pain language. Pain, $\underline{43}$ (3), 337-347.

Wilkie, D. J., Savedra, M. C., Holzemer, W. L., Tesler, M. D., \& Paul, S. M. (1990). Use of the McGill pain questionnaire to measure pain: A meta-analysis. Nursing Research, 39, 36-41.

Winefield, H. R., Katsikitis, M., Hart, L. M., \& Rounsefell, B. F. (1990). Postoperative pain experiences: Relevant patient and staff attitudes. Journal of Psychosomatic Research, 34(5), 543-552.

Wright, S. M. (1987). The use of therapeutic touch in the management of pain. Nursing Clinics of North America, 22, 705-713.

Zborowski, M. (1969). People in pain. San Francisco: Jossey-Bass. 

Ziporyn, T. (1984). Music therapy accompanies medical care. Journal of the American Medical Association, 252(8), 986-987. 


\section{APPENDIX I}

\section{INITIAL INTERVIEW}

( $75 \%$ of original size) 


\section{INITIAL INTERVIEW}

Name:

Study Number:

Unit:

Account Number:

Medical Record Number:

Admitting Diagnosis:

Admission Date:

1st Interview Date:

2nd Interview Date:

Discharge Date:

Marital/Partner Status: single $=S$ married/together $=M$ separated $=\mathrm{X}$ widowed $=\mathrm{W}$

Gender: male $=M$ female $=F$

Race:

white $=\mathrm{W}$ black $=\quad B$ other $=0$

c 1992 June H. Larrabee, PhD, RN 
INITIAL INTERVIEW

We are interested in knowing more about the kinds of people who come to The MED for care.

Before being in The MED this time, about how many times have you been admitted to a hospital?

What is your date of birth?

$$
\text { month day }-\overline{y e a r}
$$

What is the highest grade or year you finished in school?

No schooling.

Not Answered.

What is your religious preference?

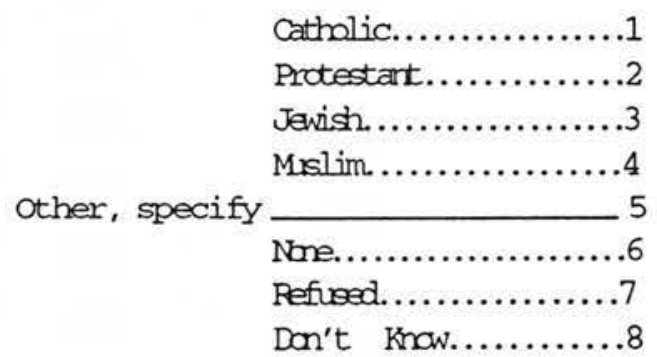

c 1992 June H. Larrabee, PhD, RN 
I have some questions which you will answer by placing a mark on a line. Here is an example of the line.

Not At All

A Whole Lot

For example, if I ask you "how much is religion a source of strength and comfort to you", and you don't think religion is a source of much strength and comfort, you would place a mark near the lower left end of the line.

How much is religion a source of strength and comfort to you?

Not At All

A Whole Lot

c 1992 June H. Larrabee, PhD, RN 


\section{INITIAL INTERVIEW}

Now, I have some questions about your health and why you are in The MED.

What is your biggest health problem that caused you to be in The MED NOW?

How bad is your

(chief symptom)?

Not Bad

At $\mathrm{All}$

Very Bad

How worried are you about this health problem?

Not Worried

At $\mathrm{All}$

Very Worried

c 1992 June H. Larrabee, PhD, RN 


\section{INITIAL INTERVIEW}

People have different hopes or goals for how being in The MED will help them with their health.

Tell me about your FIRST hope or goal for being in The MED . (If clarification needed: "For instance, you said your biggest health problem was . How do you hope being in The MED will help you with that problem?)

Tell me your SECOND hope or goal for being in The MED.

(If clarification needed: Do you have other health problems in addition to your biggest health problem? If YES, what are your hopes for how the MED can help you with those?)

Tell me your THIRD hope or goal for being in The MED.

c 1992 June H. Larrabee, PhD, RN 


\section{INITIAL INTERVIEW}

Now, I have some questions about employment.

Have you worked at a job for pay within the past year?

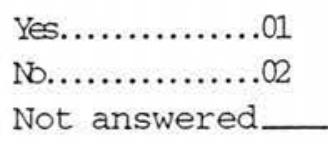

Are you CURRENTLY working at a job for pay?

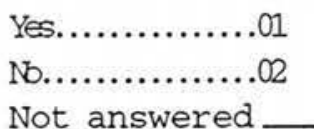

How many hours per week do you usually work?

Hours per week...

Not answered.......

Not applicable.....

We are trying to get some idea of the income range of people who come to The MED for care.

Last month, what was your PERSONAL income?

(take-home)

Dan't Know.........

Pefured.

Last month, what was your combined HOUSEHOLD income ? (take-home)

Don't know......... -

Pesired.

c 1992 June H. Larrabee, PhD, RN 
APPENDIX II

\section{EXIT INTERVIEW}

(75\% of original size) 


\section{EXIT INTERVIEW}

\section{PGA}

People have different hopes or goals for how being in the MED will help them with their health. When I first talked with you, you told me your goals for being here at the MED. I am going to remind you of each of those goals. Then, I am going to ask you how much each goal has been met. Your goal can be met all the way, not at all, or somewhere in between.

I will ask you to answer by marking a place along a line like this to show about how much each goal was met:

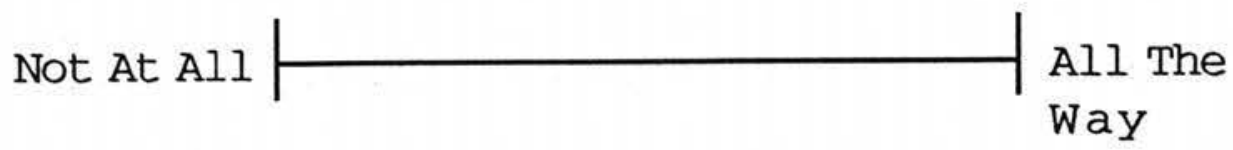

\section{$P G A$}

1. Your FIRST goal was:

This goal was met:

Not At All

All The Way

c 1992 June H. Larrabee, PhD, RN 


\section{EXIT INTERVIEW}

$P G A$

2. Your SECOND goal was:

This goal was met:

\begin{tabular}{l|l} 
Not At All & $\begin{array}{l}\text { All The } \\
\text { Way }\end{array}$
\end{tabular}

3. Your THIRD goal was:

This goal was met:

Not At All

All The

way

c 1992 June H. Larrabee, PhD, RN 


\section{EXIT INTERVIEW}

About how much of the time were you in pain while you were here?

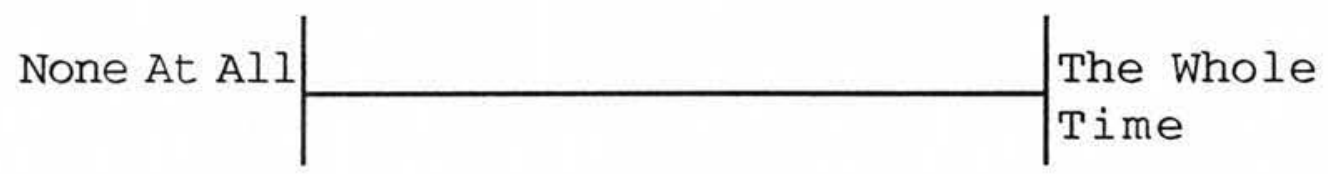

About how much pain did you have?

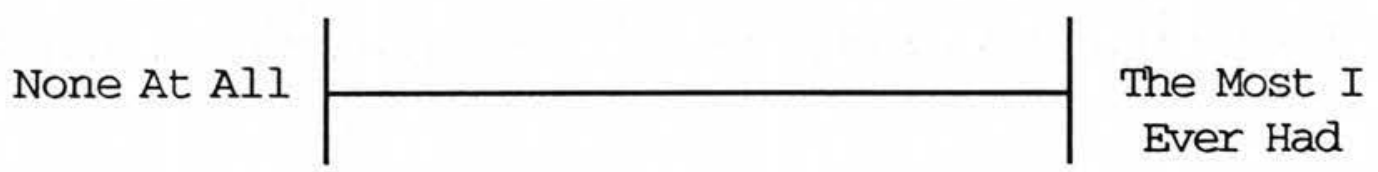

About how much pain are you in RIGHT now?

\begin{tabular}{l|l|c} 
None At All & The Most I \\
\cline { 2 - 3 } & Ever Had
\end{tabular}

c 1992 June H. Larrabee, PhD, RN 


\section{EXIT INTERVIEW}

\section{QUALITY}

Now, I would like to talk with you about the nursing care you received while you were here this time.

I will read you several statements. After each one, I would like for you to tell me how poor or how good you think the nurses did.

I will ask you to answer by marking a place along a line like this to show about how good or how poor you think your NURSING care was:

Very Poor Very Good

$$
P P Q-G
$$

Overall, how good was the nursing care you received?

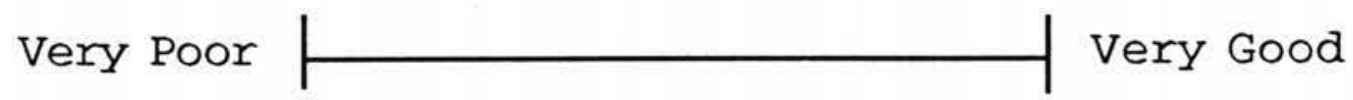

c 1992 June H. Larrabee, PhD, RN 


\section{EXIT INTERVIEW}

\section{QUALITY}

Quality is a word people use to describe how good or how poor something is. We say something has good quality or it has poor (bad) quality.

When you think of good quality in nursing care, what does that mean to you?

Other Comments:

c 1992 June H. Larrabee, PhD, RN 


\section{EXIT INTERVIEW}

\section{$\mathrm{PPO}-\mathrm{S}$}

1. The nursing staff were willing to work with you to meet your needs. (How poor or how good did they do?)

Very Poor Very Good

2. The nursing staff worked well with each other to take care of you. ( How poor or how good did they do?)

Very Poor Very Good

3. The nursing staff helped you feel comfortable or relaxed. (How poor or how good did they do?)

Very Poor Very Good

c 1992 June H. Larrabee, PhD, RN 


\section{EXIT INTERVIEW \\ $\mathrm{PPQ}-\mathrm{S}$}

4. Your nurses did a good job giving you care with things like giving you medicine and doing IVs.

(How poor or how good did they do?)

Very Poor

Very Good

5. The nurses checked on how you were doing often enough. (How poor or how good did they do?)

Very Poor Very Good

6. Your nurses were quick to help you when you called. (How poor or how good did they do?)

Very Poor Very Good

c 1992 June H. Larrabee, PhD, RN 


\section{EXIT INTERVIEW}

$\mathrm{PPQ}-\mathrm{S}$

7. Your nurses were polite, kindly, and friendly with you. (How poor or how good did they do?)

Very Poor

8. Your nurses did a good job of sharing facts about your illness with you, your family, and your doctor. (How poor or how good did they do?)

Very Poor

c 1992 June H. Larrabee, PhD, RN 
APPENDIX III

(Chart review form) 
Unit Date of Collection

Account \# Amt. of collection time

Med Record \# Dates of Care Reviewed

The nurse intervened within 30 minutes each time the patient complainted of pain . How many times should it have been done?

How many times was it done?

\%)

\section{WORKSHEET}

Time Patient Complained of pain

Nurse Responded $($ Yes $=1$ No $=0$ ) 
APPENDIX IV

(The original chart review form) 


\begin{tabular}{|l|l|}
\hline Study \# & \\
\hline Unit & \\
\hline Account \# & \\
\hline Med Record \# & \\
\hline
\end{tabular}

Data collector:

Date of collection:

Amt. of collection time:

Dates of Care Reviewed:

\begin{tabular}{|l|l|}
\hline Date/Time on Unit: & \\
\hline Date/Time D/C: & \\
\hline
\end{tabular}

Instructions:

1. Transcribe in the appropriate places on this form the following items:

a. the first 3 nursing diagnosis

b. the critical OUTCOME indicators (-if there aren't $\underline{3}$, then copy up to $\underline{2}$
noncritical indicators for a total of 3 or - if there aren't any critical indicators, copy up to 3 OUTCOME indicators.)

c. the critical NURSING INTERVENTION indicators (- or the first 3 if no critical indicators are included in the NCP)

2. Examine the NCP for "Ending Date" on outcomes and interventions. Use this information when deciding "how many times something should have been done".

3. Review the nursing care documented using the critical indicators as criteria.

Code for response

$$
1=\text { yes } 0=\text { no } \quad \mathrm{NA}=\text { not applicable (explain) }
$$


I. Nursing Diagnosis (write in)

Expected outcomes (write in)

1.

For this expected outcome:

a. How many times should it have been assessed?

b. How many times was it assessed?

c. How many times was it met?

\%)

2.

For this expected outcome:

a. How many times should it have been assessed?

b. How many times was it assessed?

c. How many times was it met?

(\%)

3.

For this expected outcome:

a. How many times should it have been assessed?

b. How many times was it assessed?

c. How many times was it met?

( \%)

Aggregate percent for outcomes

Nursing Interventions (write in):

1. How many times should it have been done? How many times was it done?

$\%$

2 .

How many times should it have been done? How many times was it done?

$\%$

3.

How many times should it have been done? How many times was it done? 
II. Nursing Diagnosis (write in)

Expected outcomes (write in)

1.

For this expected outcome:

a. How many times should it have been assessed?

b. How many times was it assessed?

c. How many times was it met?

2.

For this expected outcome:

a. How many times should it have been assessed?

b. How many times was it assessed?

c. How many times was it met?

3.

For this expected outcome:

a. How many times should it have been assessed?

b. How many times was it assessed?

c. How many times was it met?

$(\%)$

Aggregate percent for outcomes

Nursing Interventions (write in):

1. How many times should it have been done? How many times was it done?

2 . How many times should it have been done? How many times was it done?

3.

How many times should it have been done? How many times was it done? 
III. Nursing Diagnosis (write in)

Expected Outcomes (write in)

1 .

For this expected outcome:

a. How many times should it have been assessed?

b. How many times was it assessed?

c. How many times was it met?

2 .

For this expected outcome:

a. How many times should it have been assessed?

b. How many times was it assessed?

c. How many times was it met?

3.

For this expected outcome:

a. How many times should it have been assessed?

b. How many times was it assessed?

c. How many times was it met? $(\%)$

Aggregate percent for outcomes

Nursing Interventions (write in):

1. How many times should it have been done? How many times was it done? $\%$

2 .

How many times should it have been done? How many times was it done? $\%$

3.

How many times should it have been done? How many times was it done?

\%)

Aggregate percent for interventions 


\section{APPENDIX V}

IRB APPROVAL LETTER

( $75 \%$ of original size) 
Kathy L. Beck, RN,BSN

Department of Medical/Surgical Nursing

College of Nursing

UT Memphis

Dear Ms. Beck:

On May 5, 1993 the UT Memphis Administrative Section of the Institutional Review Board reviewed your application entitled "Pain and Hospital Patient's Perceptions of Quality" (IRB\#4802) which includes human subjects and/or tissue for investigative purposes.

The administrative section of the IRB determined your application to fall under the guidelines of exempt review, therefore your application was approved in this regard as complying with proper consideration of the rights and welfare of human subjects, the risk involved and the potential benefits of the study.

Any further alterations in the protocol must be promptly reported and approved by the Institutional Review Board.

\author{
Sincerely yours,

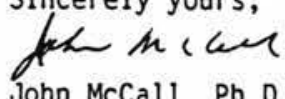 \\ John McCall, Ph.D. \\ Vice Chancellor \\ Institutional Review Board
}


APPENDIX VI

REQUEST FOR COPYRIGHT PERMISSION 
April 4, 1993

Dr. June H. Larrabee

Assistant Professor

University of Tennessee, Memphis

College of Nursing

Dear Dr. Larrabee:

I am writing to request your permission to utilize the following from your dissertation, "Hospital Patients and Nurses Perceptions of Quality":

1.Larrabee's Model of Quality - the figure.

2.Larrabee's definition of quality, value, beneficience, prudence, and justice.

3. The initial interview form (Appendix I).

4.The exit interview form (Appendix II).

All four of the above will be used, without addition or changes, in my thesis. Please send me a copyright permission letter to the address below.

Thank you for your assistance in this matter. I look forward to your response.

Sincerely,
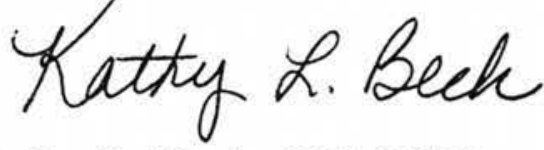

Kathy L. Beck, RN, BSN

5188 Kimbark Forest Cove

Memphis, Tennessee 38134

MSN Student 
APPENDIX VII

COPYRIGHT PERMISSION RESPONSE

( $75 \%$ of original size) 


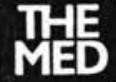

April 22, 1993

Kathy L. Beck, RN, BSN

5188 Kimbark Forest Cove

Memphis, TN 38134

Dear Ms. Beck:

You have my permission to use the copyrighted information, listed in your

April 4, 1993 letter, which is taken from my dissertation "Hospital Patients' and Nurses' Perceptions of Quality," and use in your thesis, "Pain and Hospital Patients' Perceptions of Quality", as you have described. You must acknowledge within your thesis the original source of that copyrighted information .

Sincerely,

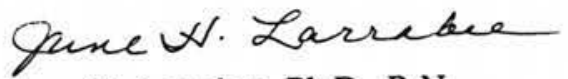
June H. Larrabee, Ph.D., R.N. Assistant Professor 


\section{VITA}

Kathy Lorraine Sartain Beck attended the University of Mississippi, at Jackson, and graduated with a BSN degree in 1987. After graduation, she began work at Mississippi Baptist Medical Center in Pedriatric Intensive Care (PICU). While in PICU, she became Advanced Cardiac Life Support Certified and CCRN certified. In 1989, she relocated to The Regional Medical Center, at Memphis (The MED) and began working in Trauma Intensive Care. While, at The MED, she accepted her current position as Nursing Care Qualtiy Coordinator.

In 1981, she was nominated for the Who's Who Among American High School Students and in 1983 for Who's Who Among American Junior College Students. In July 1993, she was invited to become a member of Sigma Theta Tau. She is also a member of the American Nurses' Association and Tennessee Nurses' Association, since 1989.

She has attended multiple quality-related conferences. In 1991 and 1993 she had poster presentations accepted to the National Nursing Qualtiy Assessment and Improvement Conference. The 1993 presentation includes an oral presentation of the poster. 